\title{
DIADOCOCINESIA ORAL E LARÍNGEA EM CRIANÇAS
}

\section{DANIELA JOVEL MODOLO}

Dissertação apresentada à Faculdade de Odontologia de Bauru, da Universidade de São Paulo, como parte dos requisitos para obtenção do título de Mestre em Fonoaudiologia. 


\section{ERRATA}

Página Linha

Onde se lê

Leia-se

30

3

$\begin{array}{lrrlrr}\text { Cada emissão } & \text { foi } & \text { gravada } & \text { Cada emissão } & \text { foi } & \text { gravada } \\ \text { durante } & \text { seis } & \text { segundos. } & \text { durante } & \text { seis } & \text { segundos. }\end{array}$

Considerando-se que as Considerando-se que as

emissões silábicas isoladas de emissões silábicas isoladas de "pa", "ta" e "ca" devam ser mais "pa", "ta" e "ca" devam ser mais fáceis do que a seqüência fáceis do que a seqüência "pataca", ou do que a repetição "pataca", ou do que a repetição de vogais. Vale ressaltar que a de vogais, foram solicitadas, emissão da trissílaba "pataca" inicialmente, as monossílabas, era acentuada na última sílaba, depois a trissílaba "pataca", foram solicitadas, inicialmente, as seguida das vogais "a", "i". Vale monossílabas, depois a trissílaba ressaltar que a emissão da "pataca", seguida das vogais "a", trissílaba "pataca" era acentuada "i”. Para evitar que a primeira na última sílaba. Para evitar que a produção tivesse desempenho primeira produção tivesse diferente das demais, a ordem de desempenho diferente das solicitação das três sílabas ("pa”, demais, a ordem de solicitação "ta" ou "ca") foi variada a partir da das três sílabas ("pa", "ta" ou "ca") distribuição aleatória das seis foi variada a partir da distribuição combinações possíveis entre aleatória das seis combinações essas emissões. possíveis entre essas emissões.

71

$$
\text { WERTZNER }{ }^{59}, 2004
$$

mais longas

mais longas
(WERTZNER $\left.{ }^{59}, 2004\right)$

mais curtas

mais curtas

Behlau M, Madazio G, Feijó D, Behlau M, Madazio G, Feijó D, Pontes P. In: Behlau M, Pontes P. Avaliação de voz. In: organizadora.

Behlau M, organizadora. 


\section{DIADOCOCINESIA ORAL E LARÍNGEA EM CRIANÇAS}

\section{DANIELA JOVEL MODOLO}

Dissertação apresentada à Faculdade de Odontologia de Bauru, da Universidade de São Paulo, como parte dos requisitos para obtenção do título de Mestre em Fonoaudiologia.

Orientadora: Prof ${ }^{a}$. Dr. ${ }^{a}$ Alcione Ghedini Brasolotto

\section{BAURU}




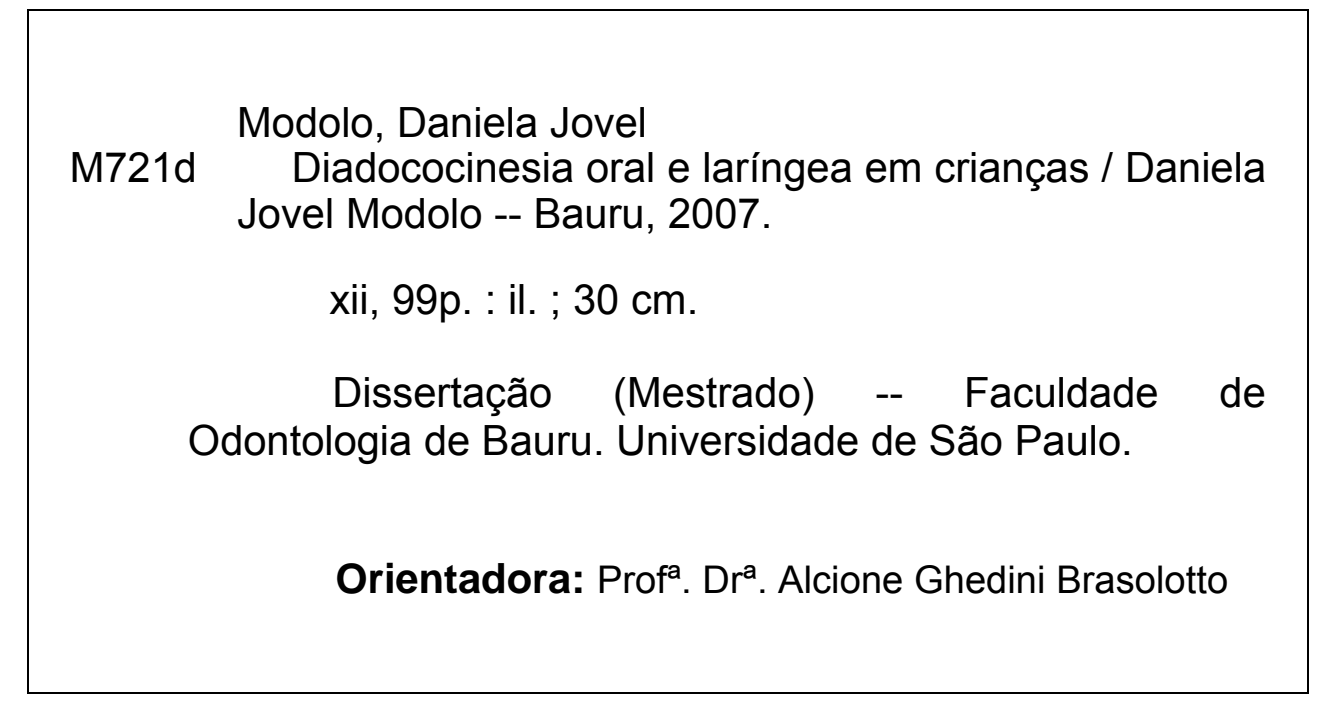

Autorizo, exclusivamente para fins acadêmicos e científicos, a reprodução total ou parcial desta dissertação/tese, por processos fotocopiadores e outros meios eletrônicos.

Assinatura:

Data:

Comitê de Ética da FOB-USP: Projeto de Pesquisa Aprovado em 30 de novembro de 2005

N. ${ }^{\circ}$ do Protocolo: $127 / 2005$ 


\begin{tabular}{|c|c|}
\hline \multirow{2}{*}{\multicolumn{2}{|c|}{$\begin{array}{l}15 \text { de março de } 1979 \\
\text { São Paulo - SP }\end{array}$}} \\
\hline & \\
\hline 1999-2002 & $\begin{array}{l}\text { Graduação em Fonoaudiologia - } \\
\text { Universidade Estadual Paulista "Julio de } \\
\text { Mesquita Filho" - UNESP - Marília - } \\
\text { SP. }\end{array}$ \\
\hline 2003-2004 & $\begin{array}{l}\text { Curso de Especialização em Voz pela } \\
\text { Faculdade de Odontologia de Bauru, } \\
\text { FOB-USP. }\end{array}$ \\
\hline $2004-2005$ & $\begin{array}{l}\text { Aperfeiçoamento em Fonoaudiologia } \\
\text { Aplicada à Clínica Odontológica, } \\
\text { Faculdade de Odontologia de Bauru, } \\
\text { FOB - USP. }\end{array}$ \\
\hline 2004-2005 & $\begin{array}{lll}\text { Prática Profissionalizante em } \\
\text { Laboratório de Voz, Faculdade de } \\
\text { Odontologia de Bauru, FOB - USP. }\end{array}$ \\
\hline 2005 & $\begin{array}{l}\text { Título de Especialista em Voz pelo } \\
\text { CFFa, } n^{\circ} 3247 / 06 \text {. }\end{array}$ \\
\hline $2005-2007$ & Curso de Pós-Graduação em \\
\hline & $\begin{array}{l}\text { Fonoaudiologia, nível de Mestrado, pela } \\
\text { Faculdade de Odontologia de Bauru, } \\
\text { FOB-USP. }\end{array}$ \\
\hline
\end{tabular}




\section{DEDICATÓRIA}

Dedico este trabalho:

Aos meus pais, Nelson Jovel Modolo e Terezinha Maria Saccon Modolo por todo amor e carinho, por terem me apoiado em mais esta decisão, principalmente por acreditarem em meus esforços e por me acolherem e me confortarem. Agradeço profundamente pelo ensinamento de valores de honestidade, humildade, respeito, educação, ética, luta e companheirismo.

Aos meus queridos irmãos Nelson e Rafael, pela amizade, cumplicidade e companheirismo, e por estarem sempre ao meu lado e fazerem parte de minha vida.

À minha querida cunhada Luciana, pela amizade, pelas palavras de incentivo e carinho.

\section{“... Cada um de nós}

\section{Compõe a sua história}

Cada ser em si carrega o dom de ser capaz

De ser feliz

Conhecer as manhas e as manhãs

O sabor das massas e das maçãs

É preciso amor pra poder pulsar

É preciso paz pra poder sorrir

É preciso a chuva para florir..."

Almir Sater e Renato Teixeira 


\section{AGRADECIMENTOS}

A Deus, por guiar meus caminhos e por me proteger em mais essa trajetória, mantendo-me firme, serena, disposta e sorridente.

À minha querida orientadora, Profa. Dr ${ }^{\mathrm{a}}$ Alcione Ghedinni Brasolotto, a quem agradeço pelo seu profissionalismo, por sua dedicação durante as orientações, e por acreditar e confiar em meu trabalho, tendo paciência em ouvir meus questionamentos. Sou grata e me sinto privilegiada em ser sua aluna.

Agradeço às professoras $\mathrm{Dr}^{\mathrm{a}}$. Giédre Berretitin-Félix, $\mathrm{Dr}^{\mathrm{a}}$. Kátia Flores Genaro, Dra . Luciana Paula Maximiamo de Vitto, que me ajudaram, orientando e enriquecendo o meu trabalho nas diversas áreas da Fonoaudiologia, por toda atenção e ensinamentos.

À Faculdade de Odontologia de Bauru, que contribuiu em minha formação profissional desde os cursos de Especialização em Voz, Prática Profissionalizante e durante o Aperfeiçoamento em Fonoaudiologia Aplicada à Clínica Odontológica.

Às crianças e seus responsáveis, aos seus Professores, às Diretoras e às Vice-diretoras e a todos os funcionários das escolas, pelo carinho, dedicação e compreensão do meu estudo.

Ao Prof. Dr. José Roberto Pereira Lauris, por colaborar na realização da análise estatística.

Às fonoaudiólogas $\mathrm{Dr}^{\mathrm{a}}$. Giédre Berretitin-Félix, $\mathrm{Dr}^{\mathrm{a}}$. Ingredi Gielow, pelas contribuições e sugestões durante a qualificação deste estudo.

Às Fonoaudiólogas Profa. Dra. Lidia Cristina da Silva Teles, Fabiane Figueiredo e Simone Bastazine e Ana Carulina, pela colaboração. 
A todos os professores do Departamento de Fonoaudiologia da FOB USP, pelo carinho, acolhimento, e valiosos ensinamentos.

A todos os Funcionários da Clínica de Fonoaudiologia e do Departamento de Fonoaudiologia, pelo carinho, respeito, e por todos os momentos agradáveis e de convivência, pois sem vocês meu trabalho não seria possível.

Aos funcionários da Biblioteca, pelos serviços prestados e toda a atenção.

A todos os funcionários da FOB-USP que me receberam muito bem, e que direta ou indiretamente contribuíram para a realização deste estudo.

Às minhas amigas Leila e Olga, pela amizade, carinho e companheirismo.

À I Turma de Mestrado em Fonoaudiologia da FOB-USP, Luciana Biral, Isabel, Mariana, Maria Cecília, Luciana Silva, Vanessa, Simone, Daphini, Ana Dolores e Josilene, pelo período de convivência e de aprendizado.

"Feliz aquele que transfere o que sabe $e$ aprende o que ensina".

Cora Coralina 


\section{SUMÁRIO}

LISTA DE FIGURAS................................................................................ viii

LISTA DE TABELAS ........................................................................... ix

RESUMO...........................................................................................

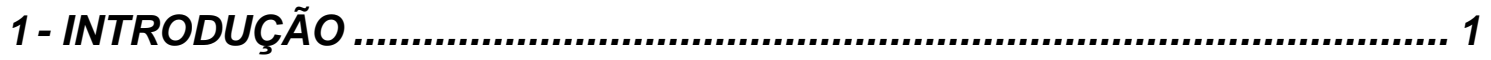

2 - REVISÃO DE LITERATURA............................................................ 7

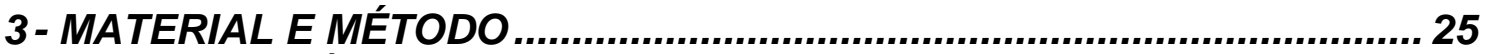

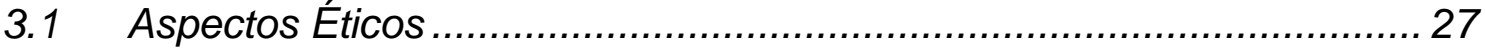

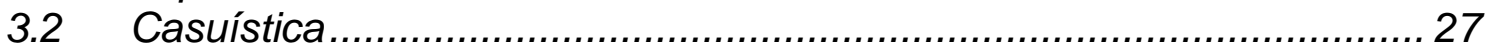

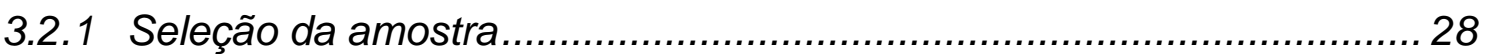

3.3 Gravação das emissões para avaliação da DDC ................................ 29

3.4 Edição das gravações das emissões "pa", "ta", "ca", "pataca", "a" e "i". 30

3.5 Análise da DDC oral e laríngea .............................................. 32

3.6 Análise Estatística ................................................................... 34

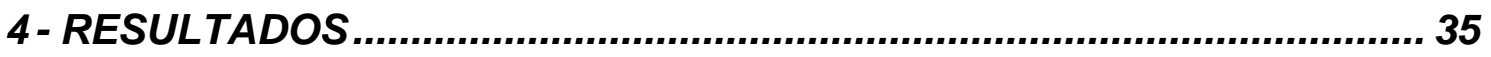

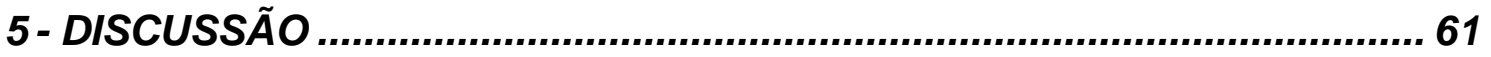

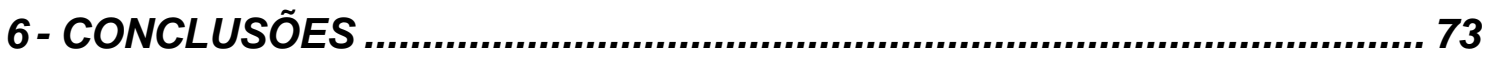

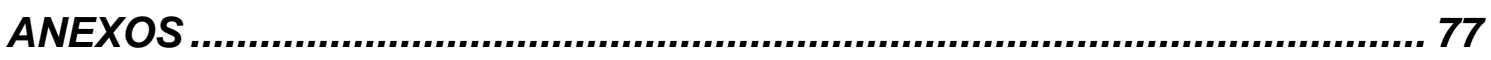

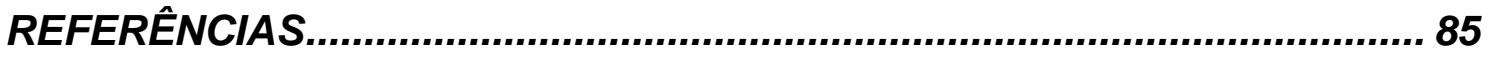

ABSTRACT

APÊNDICE 


\section{LISTA DE FIGURAS}

Figura 1: Espectrograma da emissão da seqüência "pataca", no qual se podem observar seis trissílabas no tempo de análise de 3.29 segundos .... 32

Figura 2: Gráfico do programa MSP na qual se observa o tempo (segundos) no eixo horizontal e a energia $(\mathrm{dB})$ no eixo vertical.

Figura 3: Linha de análise coincidindo com ponto de instabilidade e resultando na contagem de subpicos ( $3 \mathrm{a}$ ); Linha de análise elevada para não computar subpicos (3 b).................................................... 33

Figura 4: Parâmetros analisados para DDC de emissões monossilábicas ..... 34 


\section{LISTA DE TABELAS}

Tabela 1: Valores da DDC oral de crianças de oito anos do gênero feminino durante as emissões "pa", "ta", "ca" e "pataca".

Tabela 2: Valores da DDC laríngea de crianças de oito anos do gênero feminino durante as emissões "a" e "i".

Tabela 3: Valores da DDC oral de crianças de oito anos do gênero masculino durante as emissões "pa", "ta", "ca" e "pataca".

Tabela 4: Valores da DDC laríngea de crianças de oito anos do gênero masculino durante as emissões "a" e "i"

Tabela 5: Valores da DDC oral de crianças de nove anos do gênero feminino durante as emissões "pa", "ta", "ca" e "pataca"

Tabela 6: Valores da DDC laríngea de crianças de nove anos do gênero feminino durante as emissões "a" e "i"

Tabela 7: Valores da DDC oral de crianças de nove anos do gênero masculino durante as emissões "pa", "ta" "ca" e "pataca"

Tabela 8: Valores da DDC laríngea de crianças de nove anos do gênero masculino durante as emissões de "a" e "i"

Tabela 9: Valores da DDC oral de crianças de dez anos do gênero feminino durante as emissões "pa", "ta", "ca" e "pataca"

Tabela 10: Valores da DDC laríngea de crianças de dez anos do gênero feminino durante as emissões "a" e "i".

Tabela 11: Valores da DDC oral de crianças de dez anos do gênero masculino durante as emissões "pa", "ta", "ca" e "pataca".

Tabela 12: Valores da DDC laríngea de crianças de dez anos do gênero masculino durante as emissões "a" e "i"

Tabela 13: Valores das médias por idade e por gênero da DDC oral durante a emissão de "pa".

Tabela 14: Comparação dos resultados das tarefas da DDC oral, para a emissão monossilábica "pa", em relação à idade e gênero 
Tabela 15: Valores das médias por idade e por gênero da DDC oral durante a emissão de "ta"

Tabela 16: Comparação dos resultados das tarefas da DDC oral, para a emissão monossilábica "ta", em relação à idade e gênero

Tabela 17: Valores das médias por idade e por gênero da DDC oral durante a emissão de "ca" 54

Tabela 18: Comparação dos resultados das tarefas da DDC oral, para a emissão monossilábica "ca", em relação à idade e gênero 55

Tabela 19: Valores das médias por idade e por gênero da DDC oral durante a emissão de "pataca" 56

Tabela 20: Comparação dos resultados das tarefas da DDC oral, para a emissão trissilábica "pataca", em relação à idade e gênero 56

Tabela 21: Valores das médias por idade e por gênero da DDC laríngea durante a emissão de "a"

Tabela 22: Comparação dos resultados das tarefas da DDC laríngea, para a emissão da vogal "a", em relação à idade e gênero 58

Tabela 23: Valores das médias por idade e por gênero da DDC laríngea durante a emissão de "i"

Tabela 24: Comparação dos resultados das tarefas da DDC laríngea, para a emissão da vogal "i", em relação à idade e gênero 
RESUMO 


\section{RESUMO}

A diadococinesia (DDC) é a habilidade para realizar repetições rápidas de padrões relativamente simples de contrações musculares opostas, utilizada para avaliar a maturação e a integração neuromotora. A DDC oral e laríngea, associada aos demais procedimentos de avaliação fonoaudiológica, é um importante recurso na compreensão das manifestações dos distúrbios da comunicação. A partir disso, objetivou-se estabelecer valores de referência quanto à normalidade em relação aos resultados da avaliação da DDC oral e laríngea nos diferentes gêneros e faixas etárias de crianças falantes do português brasileiro, bem como analisar a diferença entre os gêneros e faixas etárias. Participaram 150 crianças, distribuídas nas faixas de oito, nove e dez anos de idade. A DDC oral foi avaliada por meio da repetição de "pa", "ta", "ca" e "pataca" e a DDC laríngea, pela repetição de "a" e "i". Foram utilizados os programas Motor Speech Profile Advanced e Mult Speech Main Program, da Kay Elemetrics Corp. Os parâmetros da DDC foram apresentados como média, mediana e percentil para cada emissão. A comparação entre gênero e idade foi realizada por meio da Análise de Variância a dois critérios e do teste de Tuckey. Quanto à DDC oral, a análise estatística dos resultados demonstrou que, com o avanço da idade: houve aumento do número de emissões de monossílabas por segundo, redução do tempo médio entre essas emissões; houve aumento do coeficiente de variação do período durante a sílaba "ca" e aumento do coeficiente de variação do pico da intensidade para a sílaba "ta". 0 número de emissões por segundo da monossílaba "ta" foi maior para as meninas que para os meninos. Na emissão da trissílaba, o número de emissões por segundo foi diferente entre os gêneros e, considerando-se os subgrupos de idade e gênero, as meninas de oito anos apresentaram menor número de emissões que todos os demais subgrupos. Quanto à DDC laríngea, com o avanço da idade houve aumento do número de emissões por segundo e períodos mais curtos da vogal "i" para as meninas; menor valor do desvio padrão do período e da perturbação do período para essa mesma vogal. Conclui-se que foi possível estabelecer os valores de normalidade da DDC oral e laríngea para o grupo de crianças estudado e que houve diferenças quanto ao gênero e à idade, o que demonstra que o desenvolvimento da DDC oral e laríngea deve ser considerado na avaliação da comunicação oral de crianças.

Palavras-chave: Avaliação. Testes de articulação da fala. Voz 


\section{1 - INTRODUÇÃO}




\section{INTRODUÇÃO}

A fala requer a participação de várias estruturas, incluindo a contração coordenada de um grande número de grupos musculares para a sua produção, tais como dos músculos dos lábios, língua, véu palatino, faringe, laringe, bem como, da respiração, e a contração desses grupos musculares é controlada por impulsos nervosos que se originam em áreas motoras do córtex cerebral e são transmitidos aos músculos, através do sistema-motor (MURDOCH $\left.{ }^{40}, 1997\right)$.

O controle dos movimentos desses grupos musculares é requisitado durante a diadococinesia (DDC), a qual é definida como sendo a habilidade para realizar repetições rápidas de padrões relativamente simples, de contrações musculares opostas (BAKEN; ORLIKOFF ${ }^{4}$, 2000), sendo necessário, para a realização dessa tarefa, cessar um determinado impulso motor e substituí-lo pelo seu oposto (LEEPER; JONES ${ }^{31}$, 1991). Em relação à fonoarticulação, a DDC é utilizada para avaliar a maturação e a integração neuromotora, promovendo um índice acústico da velocidade do movimento e do posicionamento articulatório (BAKEN; ORLIKOFF $\left.{ }^{4}, 2000\right)$.

A avaliação da DDC oral inclui testes fonoarticulatórios que avaliam a função dos lábios e da língua, utilizando a repetição de sílabas (PRATHANEE; THANAVIRATANANICH; PONGJANYAKUL ${ }^{46}$, 2003). Por sua vez, a DDC laríngea avalia o controle para realizar afastamento e aproximação de pregas vocais de forma rápida e regular (BAKEN; ORLIKOFF ${ }^{4}, 2000$ ), sendo freqüentemente realizada a partir da repetição das vogais (KREUL ${ }^{29}, 1972$, LEEPER; HEENEMAN; REYNOLDS ${ }^{30}$, 1990, LEEPER; JONES ${ }^{31}, 1991$, LEEPER et al. ${ }^{32}, 1996$, PEREIRA et al. ${ }^{44}, 2004$; DEPRET $\left.{ }^{13}, 2005\right)$.

A DDC, associada aos demais procedimentos de avaliação fonoaudiológica, tem sido evidenciada como um recurso importante na compreensão das manifestações dos distúrbios da comunicação (PORTNOY; ARONSON ${ }^{45}$, 1982, WIT et al. ${ }^{65}$, 1993, ACKERMANN et al. ${ }^{1}, 1993$, ACKERMANN; HERTRICH; HEHR ${ }^{2}$, 1995, LEEPER et al. ${ }^{32}$, 1996, THOONEN et al. $^{56}$, 1996; BRASOLOTTO; BEHLAU ${ }^{7}$, 2001; FAWCETT; NICOLSON ${ }^{19}$, 2002, ZIEGLER ${ }^{69}$, 2002, HARTELIUS; LILLVIK ${ }^{23}$, 2003, LUNDY et al. ${ }^{35}$, 2004, PEREIRA et al. ${ }^{44}$, 2004, ROSEN; KENT; DUFFY ${ }^{4}$, 2005). O estudo da DDC, 
em pacientes com várias doenças neurológicas, indica que os resultados da tarefa da DDC oral representam uma medida sensível da deficiência motora orofacial (ACKERMANN; HERTRICH; HEHR², 1995). Ressalta-se também a relação entre a inteligibilidade da fala e os padrões diadococinéticos, uma vez que as taxas mais lentas podem estar correlacionadas a pacientes com baixa inteligibilidade de fala (DWORKIN; ARONSON ${ }^{15}$, 1986). Além disso, a análise da DDC de pregas vocais permite avaliar a integridade neuromuscular laríngea do indivíduo (LEEPER; JONES ${ }^{31}$, 1991).

Para a realização da avaliação da DDC, solicita-se a repetição de uma determinada emissão o mais rápido possível e de forma clara (MULLIGAN et al. ${ }^{39}$, 1994, YARUSS; LOGAN ${ }^{67}$, 2002). Entretanto, dentre os vários estudos que utilizaram a DDC, verifica-se que há uma variedade quanto ao método em relação às emissões solicitadas. São relatadas as emissões de algumas sílabas, vogais e palavras com e sem significado (WILLIAMS; STACKHOUSE ${ }^{61}$, 1998, COHEN; WATERS; HEWLETT ${ }^{12}$, 1998, WILLIAMS; STACKHOUSE $^{62}$, 2000, CARRARA-de-ANGELIS ${ }^{10}$, 2000, BRASOLOTTO; BEHLAU ${ }^{7}, 2001$, PRATHANEE; THANAVIRATANANICH; PONGJANYAKUL ${ }^{46}$, 2003, MOURÃO ${ }^{38}, 2002$, PEREIRA et al. ${ }^{44}, 2004$, DEPRET $\left.{ }^{13}, 2005\right)$, sendo as mais citadas as sílabas "pa", "ta", "ca" e a trissílaba "pataca" para a DDC oral, e a vogal "a" para a DDC laríngea. Entretanto, ressalta-se que há uma diferença na produção fonética em relação à emissão utilizada em cada língua (LEEPER; HEENEMAN; REYNOLDS ${ }^{30}$, 1990, LEEPER; JONES ${ }^{31}, 1991$, RENOUT et al. ${ }^{51}$, 1995; COEHEN; WATERS; HEWELETT ${ }^{12}$, 1998, THOONEN et al. ${ }^{57}$, 1999, BRASOLOTTO; BEHLAU ${ }^{7}$, 2001, HARTELIUS; LILLVIK ${ }^{23}$, 2003, PRATHANEE; THANAVIRATANANICH; PONGJANYAKUL ${ }^{46}, 2003$, ROSEN; KENT; DUFFY ${ }^{54}$, 2005, DEPRET $\left.{ }^{13}, 2005\right)$.

Outra variação em relação ao método refere-se à escolha do trecho da emissão a ser analisado, uma vez que a análise pode ser feita sobre a primeira ou a segunda prova, sobre a média de três provas, bem como sobre a melhor prova; pode-se também excluir o trecho inicial e final da amostra ou a primeira sílaba (PTACEK et al. ${ }^{49}$, 1966, FLETCHER; MELDRUM ${ }^{20}$, 1968; FLETCHER ${ }^{21}$, 1972, DWORKIN; ARONSON; MULDER ${ }^{14}, 1980$, OLIVER et al. ${ }^{42}$, 1985, HALE et al. ${ }^{22}$, 1992, WIT et al. ${ }^{64}$, 1994, ACKERMANN, HERTRICH; HEHR $^{2}, 1995$, ZIEGLER ${ }^{69}, 2002$, PEREIRA et al. $\left.{ }^{44}, 2004\right)$. 
A DDC pode ser realizada solicitando-se a repetição da emissão em determinado tempo - rate-by-time (BLOMQUIST ${ }^{6}$, 1950, DWORKIN ${ }^{17}, 1978$, DWORKIN ${ }^{18}$, 1980, ROBBINS; KLEE ${ }^{53}$, 1987, PRATHANEE ${ }^{47}$, 1998, BRASOLOTTO; BEHLAU ${ }^{7}, 2001$, PEREIRA et al. ${ }^{44}$, 2004), ou um número definido de emissões durante o tempo que for necessário - time-by-count (FLETCHER $^{21}$, 1972, PRATHANEE; THANAVIRATANANICH; PONGJANYAKUL ${ }^{46}$, 2003). O cálculo da DDC é apresentado em número de emissões por determinado tempo, o que é denominado de taxa de DDC, a qual representa a velocidade de repetição das emissões.

Além da análise quantitativa do número de emissões e/ou tempo para a realização das emissões, pode ser realizada também a análise da DDC de forma qualitativa, a qual fornece informações relevantes sobre o controle motor das estruturas envolvidas durante a fonoarticulação (BLOMQUIST ${ }^{6}$, 1950, WHITEHILL; TSANG ${ }^{60}$, 2002). A análise das repetições quanto à regularidade e estabilidade pode ser realizada subjetivamente pela percepção auditiva, ou por meio de medidas objetivas (BRASOLOTTO; BEHLAU ${ }^{7}, 2001$, LUNDY et al. ${ }^{35}, 2004$, PEREIRA et al. ${ }^{44}$, 2004).

Ainda, em relação ao método de cálculo da DDC, para contar as emissões, pode ser utilizada a reprodução do áudio em velocidade reduzida, para, posteriormente, realizar-se o cálculo da DDC (CANNING; ROSE ${ }^{8}, 1974$, DWORKIN; CULATTA $\left.{ }^{16}, 1985\right)$, bem como o apoio visual da onda sonora (PTACEK et al. ${ }^{49}$, 1966, FLETCHER ${ }^{21}$, 1972, ROBB; HUGHES; FRESE ${ }^{52}$, 1985, CHUMA et al. ${ }^{11}$, 1999). Alguns programas computadorizados fazem a extração automática dos valores da DDC (MOURÃO ${ }^{38}, 2002$, LUNDY et al. ${ }^{35}$, 2004, DEPRET $\left.{ }^{13}, 2005\right)$.

O teste da DDC é freqüentemente utilizado na avaliação de crianças com distúrbios da comunicação, envolvendo quadros de alterações neurológicas, alterações fonético-fonológicas e disfluência (PRINS ${ }^{48}, 1962$, YOSS; DARLEY ${ }^{68}$, 1974; DWORKIN ${ }^{17}, 1978$, DWORKIN ${ }^{18}, 1980$, WIT et al. ${ }^{65}$, 1993, WOLK; EDWARDS; CONTURE ${ }^{66}$, 1993, THOONEN et al. ${ }^{57}$, 1999, BRASOLOTTO; BEHLAU $\left.{ }^{7}, 2001\right)$. Também tem sido utilizada em adultos com diagnóstico de doenças neurológicas e laríngeas (CANTER ${ }^{9}, 1965$, DWORKIN; ARONSON; MULDER ${ }^{14}$, 1980, DWORKIN; ARONSON ${ }^{15}$, 1986; LEEPER; HEENEMAN; REYNOLDS ${ }^{30}$, 1990; CARRARA-de-ANGELIS ${ }^{10}, \quad 2000$, 
ACKERMANN; HERTRICH; HEHR ${ }^{2}, 1995$, RAY $^{50}, 2002$, ZIEGLER $^{69}, 2002$, ROSEN; KENT; DUFFY ${ }^{54}$, 2005).

De modo geral, a tarefa da DDC pode ser utilizada na avaliação e na evolução terapêutica em casos com distúrbios da comunicação. Para isso, faz-se necessária a compreensão do desempenho da DDC em indivíduos que não apresentam problemas de comunicação. Alguns autores descrevem o desenvolvimento da DDC em diversas faixas etárias, tanto em crianças (BLOMQUIST ${ }^{6}$, 1950, WILLIAMS; STACKHOUSE ${ }^{62}$, 2000, YARUSS; LOGAN ${ }^{67}$, 2002, PRATH ANEE; THANAVIRATANANICH; PONGJANYAKUL $\left.{ }^{46}, 2003\right)$, quanto em adultos e idosos (SHANKS ${ }^{55}, 1970$, PRATHANEE ${ }^{47}, 1998$ ).

Para entender o processo da maturação neuromotora, faz-se necessário iniciar o estudo verificando como se dá este processo em crianças, sem alterações neuromotoras ou de comunicação, a fim de se compreender, em estudos posteriores, o que ocorre com as populações que apresentam distúrbios da comunicação. Uma vez que não foram encontrados, na literatura nacional, estudos referentes à padronização dos testes da DDC oral e laríngea em crianças, o presente estudo pretende fornecer os dados necessários à interpretação desses testes.

Neste estudo, foi realizada a avaliação da DDC oral e laríngea de crianças de ambos os gêneros, falantes do português brasileiro, com o intuito de:

- Determinar os valores de referência quanto à normalidade para os diferentes gêneros e faixas etárias;

- Verificar possíveis diferenças nesses valores entre os gêneros e entre as faixas etárias. 
2 - REVISÃO DE LITERATURA 


\section{REVISÃO DE LITERATURA}

BLOMQUIST $^{6}, 1950$, estabeleceu o número de emissões por segundo para movimentos diadococinéticos, produzidos por sessenta crianças de nove a onze anos, sem alterações de fala. Os sons /p/, /t/, /k/ e /ptk/ foram representados em um quadro negro, e as crianças foram solicitadas a repetir cada seqüência de forma mais rápida e regular possível, por três vezes, tendo sido considerada a média das três provas. Os resultados mostraram que o número de sons produzidos, por segundo, aumentou com a idade. Houve diferença, estatisticamente significante, no grupo de meninas, comparando-se as idades de nove e de onze anos para o som [pə], para os meninos, houve diferença significante entre nove e onze anos de idade em todos os sons testados; não houve diferença significante entre os gêneros, mas os meninos apresentaram escores um pouco mais altos do que as meninas para todos os sons, exceto em [pӘtӘkə]. Todos os sons foram emitidos em velocidade semelhante, sendo a média mais baixa para o som [kə]. O autor ressaltou a importância de se considerar também o ritmo dos movimentos da DDC para análise.

IRWIN; BECKLUND ${ }^{27}, 1953$, estabeleceram padrões de desempenho da DDC para crianças de seis a quinze anos, sem manifestação de alterações de fala. Os sons de fala /pə/, /tə/ e / $/ \mathrm{k} /$ e os sons de bater com a mão direita, com a esquerda e com ambas as mãos, foram registrados por um aparelho denominado Sylrater. Três provas de cinco segundos foram realizadas para cada som, sendo considerada a prova com maior número de sons por segundo. A taxa da DDC aumentou de acordo com a idade, e os autores consideraram a existência de uma possível tendência dos meninos mais novos serem mais lentos que as meninas da mesma faixa etária, e dos meninos mais velhos serem mais rápidos em relação às meninas de igual faixa etária.

PRINS ${ }^{48}$, 1962, investigou se crianças com vários tipos de alterações articulatórias demonstravam diferenças em diversos níveis, inclusive no desempenho de tarefas motoras e auditivas. O grupo experimental era composto de 92 crianças de três a seis anos de idade, com distúrbio articulatório, subdivididas em três grupos, de acordo com a alteração 
articulatória: a) interdentalização lingual durante os fonemas /s/ e /z/ ; b) omissões; c) substituições. O grupo controle consistia de 71 crianças entre três e sete anos de idade, sem distúrbio articulatório. Dentre várias avaliações, foi realizado o teste da DDC oral, para o qual foi solicitada a repetição de $[\mathrm{p} \wedge$ ], $[\mathrm{t} \wedge],[\mathrm{k} \wedge],[\mathrm{p} \wedge \mathrm{t} \wedge], \mathrm{e}[\mathrm{p} \wedge \mathrm{t} \wedge \mathrm{k} \wedge]$. Foi considerado como escore o número de repetições de cada som no período de cinco segundos. Foram encontradas diferenças significantes entre os subgrupos de crianças com diferentes alterações articulatórias e entre os subgrupos comparados ao grupo controle, sendo que o grupo experimental apresentou menor taxa da DDC, em comparação ao grupo controle.

FLETCHER; MELDRUM ${ }^{20}$, 1968, realizaram estudos fisiológicos, incluindo articulação da fala e coordenação motora oral em movimentos diadococinéticos, para validar um procedimento de medida do frênulo da língua. A partir de medidas de dimensão sublingual, quarenta crianças foram separadas em dois grupos, de acordo com o comprimento do frênulo da língua. Foram coletadas vinte repetições de $\mathrm{I} \wedge$ e $\mathrm{t} \wedge$, quinze repetições de $p \wedge t \partial ; \mathrm{t} \wedge k \partial$, dez repetições de p^tӘkə e, posteriormente, foi verificado o tempo para realizar essas emissões, em segundos. Em geral, a taxa da DDC de repetições silábicas foi mais baixa para os sujeitos com frênulo de língua limitado.

FLETCHER ${ }^{21}$, 1972, utilizou a técnica time-by-count, tempo transcorrido para produzir um número determinado de emissões, para avaliar a DDC em 24 meninas e 24 meninos de idades entre seis e treze anos. Foi solicitada a repetição das seguintes produções: vinte monossílabas, quinze dissílabas e dez trissílabas. Estas emissões foram contadas e cronometradas, sendo realizada simultaneamente, a gravação para posterior análise oscilográfica. A ordem de solicitações foi variada, sendo realizada a solicitação das emissões em ordem crescente (mono, di e trissílabas) para metade das crianças e, em ordem aleatória, para a outra metade. Foi encontrada uma diminuição no tempo utilizado para produção das emissões, de acordo com o avanço das idades, exceto para a faixa de seis a sete anos. Meninas tenderam a ser mais rápidas na produção de monossílabos e meninos mais rápidos nas demais emissões. Comparando os resultados entre meninos e meninas, houve diferença significante para as sílabas $f \wedge ; \mid \Lambda$, $p \wedge t \partial$ e $p \wedge k \partial$. A ordem de apresentação dos sons não proporcionou diferença significante, bem como as 
análises realizadas, utilizando-se o cronômetro e o osciloscópio, não foram estatisticamente diferentes para todas as emissões, à exceção da sílaba /ka/. O autor concluiu que o time-by-count pode produzir um cálculo preciso da produção silábica de DDC.

YOSS; DARLEY ${ }^{68}, 1974$, buscaram identificar comportamentos que pudessem distinguir entre apraxia de desenvolvimento da fala do distúrbio articulatório "funcional". Participaram trinta crianças de cinco a dez anos de idade, com alterações articulatórias de moderado a severo e também um grupo controle de trinta crianças sem alterações articulatórias. As crianças foram submetidas a uma bateria de testes, sendo um dos aspectos a DDC oral, avaliada por meio da repetição das sílabas $/ \mathrm{p} \wedge /$, /t $\wedge /, / k \wedge /$ e $/ p \wedge$ t $\wedge$ kə/. 0 número de sílabas por segundo de $/ \mathrm{p} N$, /t/ $/$, /kN, para o grupo com alteração articulatória, foi significativamente mais baixo do que para o grupo controle. Somente dez crianças no grupo, com alterações articulatórias, produziram a ordem de sílaba correta para $/ p \wedge t \wedge k \partial /$, e as crianças do grupo controle produziram significativamente maior número de emissões para essa seqüência. Os autores consideraram que as medidas da DDC oral evidenciaram progressão da velocidade com o aumento da idade. Em outra análise, os autores subdividiram as crianças em um grupo com alterações articulatórias que apresentavam bom desempenho nos movimentos orais voluntários isolados, e outro grupo de crianças que apresentavam desempenho inferior nesses movimentos. Esse estudo mostrou diferença estatisticamente significante entre os dois grupos quanto às tarefas de movimentos voluntários isolados e seqüenciais. De acordo com os autores, os achados dessa análise delinearam o grupo de crianças que deu suporte ao uso do termo "apraxia desenvolvimental da fala", sendo a DDC oral um dos achados que pode prover pistas para o diagnóstico.

CANNING; $\mathrm{ROSE}^{8}, 1974$, estabeleceram normas relacionadas à velocidade de movimentos específicos dos lábios e da língua em trezentas crianças, sem alterações de fala, de quatro anos e meio a nove anos e meio e de treze anos e meio a catorze anos e meio. O teste da DDC foi realizado por três tipos de provas: movimentos de lateralização da língua tocando as comissuras labiais; dez repetições das consoantes /t/,/j/,/k/ e /l/, /w/ e /p/, sendo selecionada para análise, a parte mais rápida de cada série; dez repetições 
corretas da seqüência /p, t, k/, ou a palavra "buttercup" para crianças abaixo de cinco anos e meio. Ao comparar as tarefas da DDC em relação aos gêneros, não foram encontradas diferenças significantes, havendo diferença quando se compararam as idades. Foram observados pequenos aumentos nas velocidades médias dos grupos até a faixa etária de oito anos e meio a nove anos e meio, e um aumento maior para a faixa etária de treze anos e meio a catorze anos e meio, embora os resultados sugiram que, de nove anos e meio a treze anos e meio, a melhora tenha sido reduzida. Esse achado não foi observado para a habilidade em seqüencializar as três consoantes e não houve correlação entre a velocidade de repetição de consoantes simples e movimentos isolados da língua. Segundo os autores, a criança que possui falha específica, ao seqüencializar os sons da fala, não necessariamente evidencia problema no controle motor, uma vez que elas são capazes de emitir fonemas isolados.

MASON et al. ${ }^{36}, 1977$, apresentaram uma proposta de triagem, para uso na clínica odontológica, para avaliar o desenvolvimento da fala de crianças. Dentre outros procedimentos, foi indicada a verificação da capacidade neuromotora da fala, por meio do teste da DDC oral. Às crianças foi solicitada a repetição rápida das seqüências "puh"; "tuh"; "puh-tuh-kuh", quinze vezes cada seqüência e, caso as crianças apresentassem dificuldade na última seqüência, poderiam produzir "pat-a-cake". De acordo com os autores, o teste da DDC oral fornece informações sobre o nível de maturação dos componentes neuromotores das estruturas orais utilizadas durante a produção do som.

DWORKIN $^{17}$, 1978, avaliou a relação entre a força de protrusão da língua e a taxa da DDC da língua em 45 crianças com ceceio anterior e com idades entre sete anos e seis meses a doze anos e igualmente em 45 crianças sem história de alteração de fala e que demonstraram habilidade articulatória adequada. No teste da DDC foi solicitada a repetição das sílabas $/ \mathrm{t} / \mathrm{N}, / \mathrm{d} / \mathrm{N}$, $/ \mathrm{k} N /, \mathrm{g} N /$, por três vezes, por um período de três segundos, tendo sido calculada a média das três provas. Os resultados indicaram que o grupo controle apresentou maior força da língua e maior número de emissões na DDC. Não houve diferença significante quanto à força da língua e a taxa média da DDC, entre meninos e meninas sem alteração de fala ou com ceceio anterior, nas faixas etárias estudadas. Com o aumento da idade, houve uma 
tendência da força de língua e da taxa média da DDC aumentarem semelhantemente, para o grupo sem alteração de fala e para o grupo com ceceio anterior. Porém, a performance da força da língua e da DDC foi um pouco maior para meninas que meninos em cada grupo. Os autores sugerem que a disdiadococinesia lingual pode ser parcialmente causada pela diminuição na força da musculatura da língua, e que a fraqueza muscular da língua ou hipotonicidade, contribuem para padrões inexatos de movimentos durante a articulação.

DWORKIN ${ }^{18}$, 1980, correlacionou a força de protrusão da língua, taxa da DDC da língua e a porcentagem de erro para o fonema /s/ em 45 crianças com ceceio anterior de vários graus de severidade e em 45 crianças sem história de alteração de fala, com as idades entre sete anos e seis meses a doze anos, em ambos os grupos. No teste da DDC foi utilizado o mesmo método do estudo de DWORKIN ${ }^{17}$, 1978. Em comparação às crianças que não apresentavam ceceio, os resultados mostraram menor média de força da língua para as crianças que apresentavam ceceio. As crianças com ceceio severo exibiram taxa média da DDC significativamente mais lenta para cada sílaba realizada, da mesma forma que as crianças com ceceio acentuado e leve, exceto para a sílaba /dA/. Os resultados deste estudo apontam a interrelação entre ceceio anterior, fraqueza da língua, e taxas da DDC da língua reduzidas.

WILLIAMS; INGHAM; ROSENTHAL ${ }^{63}$, 1981, reproduziram o estudo de YOSS; DARLEY ${ }^{68}$, 1974, encontrando que o número de emissões por segundo das sílabas /p $N$, /t/ $N$, /kN para o grupo com alteração articulatória, foi menor que o grupo controle. Somente vinte crianças do grupo com alteração articulatória produziram a ordem de sílaba correta para $/ \mathrm{p} \wedge \mathrm{t} \wedge \mathrm{k} \partial /$; já a taxa para essas emissões das crianças do grupo controle, não foi muito maior. Posteriormente, o grupo com alterações articulatórias foi re-dividido, como descrito por Yoss; Darley ${ }^{68}$, 1974. O grupo com alteração articulatória com bom desempenho nos movimentos orais isolados apresentou taxa da DDC mais elevada durante a produção do /ka/. Os autores concluíram não ser possível identificar a presença de apraxia de desenvolvimento da fala nas crianças desse estudo. 
DWORKIN; CULATTA ${ }^{16}, 1985$, determinaram a ocorrência de sinais de alterações estruturais e/ou neuromusculares nos mecanismos de fala de seis meninas, com média de idade de sete anos e oito meses e dezoito meninos, com média de idade de sete anos e sete meses, com diagnóstico de distúrbio articulatório funcional, caracterizado por omissões, distorções ou substituições de fonemas. As crianças foram comparadas a um grupo controle formado por vinte meninas, com média de idade de sete anos e sete meses e catorze meninos, com média de idade de oito anos e um mês, sem alterações de fala e sem histórico de alterações de fala ou linguagem. As crianças foram submetidas a testes de articulação, de DDC, de força de língua e à avaliação do mecanismo oral. Em relação à DDC, cada criança foi solicitada a repetir as sílabas $/ \mathrm{p} N /$, $/ \mathrm{t} / /, / \mathrm{k} N /$, por três vezes. Não foram encontradas diferenças significantes entre os gêneros ou entre os grupos, sem e com distúrbio articulatório. Os autores sugerem que outras variáveis devem ser investigadas, a fim de contribuir para a compreensão do mecanismo alterado da fala.

OLIVER et al. ${ }^{42}, 1985$, estudaram a esterognosia oral e a DDC dos lábios e da língua de 176 crianças, de oito a dezesseis anos, e vinte adultos jovens. Todos os casos estudados não deveriam ter alterações de fala, utilizar aparelho ortodôntico ou prótese dentária, assim como não ter fissura labiopalatina. Em relação à DDC, utilizaram dez repetições das seguintes seqüências: "pa pa", "oo ee" e "ka la". Os sujeitos também foram solicitados a realizar, por cinco vezes, as seqüências de movimentos da língua: protrusão e retração, elevação e abaixamento, e lateralização. O tempo transcorrido para a realização das seqüências de movimentos envolvendo atividade de fala e não fala, foi registrado utilizando-se um cronômetro. Os achados mostraram que com o aumento da idade, verificou-se um aumento na porcentagem de formas identificadas corretamente no teste de esterognosia e diminuição no tempo de DDC, para todas as seis tarefas da DDC juntas; o grupo feminino foi mais lento que o masculino no teste da DDC e não houve correlação entre a DDC e a esterognosia oral.

ROBBINS; KLEE ${ }^{53}$, 1987, estudaram a avaliação da habilidade motora orofaríngea em noventa crianças de dois anos e seis meses a seis anos e onze meses, com desenvolvimento normal, as quais foram avaliadas quanto à estrutura e à função do trato vocal, utilizando tarefas de fala e tarefas não 
lingüísticas. Também foram avaliados a DDC e o tempo máximo de fonação. Em relação às tarefas da $D D C$, as crianças foram solicitadas a repetir, durante três segundos, cada monossílabo $(/ \mathrm{p} / / / \mathrm{t} / N, / \mathrm{k} / /)$ e cada polissílabo (/pӘrӘKӘK/ e patticake), sendo calculado o número de repetições por segundo para cada emissão. De acordo com os autores, nenhum aumento significante foi encontrado no escore estrutural total com a idade, mas houve aumento estatisticamente significante no escore funcional total, com o aumento da idade. Em relação à DDC, as repetições de /kN/, /pӘrəKəK/ e patticake, demonstraram maior número de repetições por segundo, com o aumento da idade.

HENRY $^{25}, 1990$, avaliou a DDC oral, a habilidade rítmica não lingüística e a memória auditiva seqüencial de sessenta crianças sem alterações da fala e linguagem, e de trinta crianças com distúrbio severo da fala, com idade entre três e cinco anos. A DDC foi analisada pelo número de

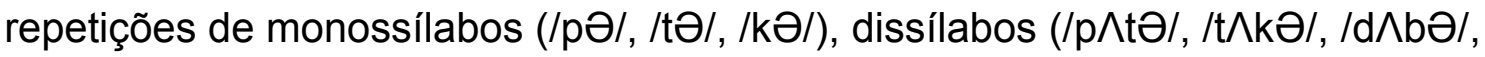

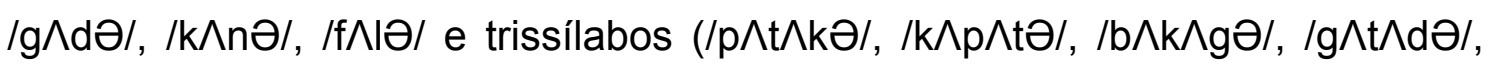
$\mathrm{s} \wedge \mathrm{f} \wedge \mathrm{p} / /)$, realizadas no tempo de dez segundos cada. A avaliação do ritmo foi constituída de repetições da sílaba /ma/ em diferentes combinações e, para a avaliação da memória auditiva, foi utilizada a repetição de seqüência de dígitos. Os resultados mostraram que as crianças com distúrbio da fala apresentaram pior desempenho nas avaliações da DDC, ritmo e memória, quando comparadas às crianças sem alterações de fala e linguagem. A correlação entre idade, gênero, habilidade rítmica, taxa da DDC e memória auditiva demonstrou, para as crianças sem alterações de fala e linguagem, intercorrelações mais fortemente significantes entre a DDC total e idade, DDC total e ritmo, ritmo e memória auditiva, não sendo encontrada correlação para o fator gênero. Nas crianças com distúrbio de fala, a DDC total foi menos fortemente correlacionada à idade, em comparação às crianças sem alterações de fala e linguagem. Segundo os autores, pode haver uma relação entre memória auditiva, DDC e ritmo.

HASELAGER; SLIS; RIETVELD ${ }^{24}$, 1991, investigaram a relação entre as taxas da DDC e da fala espontânea com a idade. Participaram quarenta crianças, divididas em quatro grupos, com cinco, sete, nove, e onze 
anos de idade, cada grupo consistindo de cinco meninas e cinco meninos, sem história de alteração de fala ou audição. As amostras da fala espontânea foram classificadas em emissões curtas, médias e longas. A taxa da DDC foi calculada por meio das sílabas /pa/, /ta/ /ka/, /fa/, /sa/ e /xa/, sendo a extensão mínima na tarefa da DDC, uma série de seis sílabas. As taxas da DDC e da fala espontânea foram expressas em sílabas por segundo. Foi observada tendência do número de silabas por segundo para fala espontânea aumentar com a idade e com a extensão das emissões. Foi observado que a taxa da DDC aumentou mais fortemente com a idade do que a taxa da fala espontânea. Meninos e meninas foram considerados semelhantes em seu desempenho quanto à taxa da fala e da DDC.

HALE et al. $^{22}$, 1992, examinaram o comportamento motor oral, verificado pela avaliação da DDC e os aspectos miofuncionais orais dos lábios e da língua, durante o repouso e durante as funções de deglutição e fala, a fim de determinar se existe relação entre os aspectos avaliados. Participaram desse estudo 133 alunos, de ambos os gêneros, com média de idade de oito anos e quatro meses, sem prejuízos sensoriais ou motores. Foi calculado o tempo transcorrido para produzir um número determinado de emissões durante a tarefa da DDC. A velocidade de produção foi analisada pelas emissões $/ \mathrm{p} \Lambda /$; $/ \mathrm{p} \wedge \mathrm{t} \wedge / \mathrm{e} / \mathrm{p} \wedge \mathrm{t} \wedge \mathrm{k} \wedge /$, tendo sido considerada a média das três provas. Quanto ao aspecto miofuncional, foi verificada a postura de repouso dos lábios e língua, bem como a postura da língua para a produção dos fonemas linguo-alveolares e para a deglutição. Os resultados demonstraram que não houve diferenças significantes entre os gêneros para a DDC; o tempo para a produção da sílaba /p $/$ foi maior quando associado à postura de repouso dos lábios afastados, assim como o tempo para produção de trissílabas também foi maior, quando correlacionado com a interposição da língua, tanto no repouso como na deglutição.

WIT et al. ${ }^{65}$, 1993, avaliaram o tempo máximo de fonação, a freqüência fundamental e a DDC, para diferenciar grupos compostos por onze crianças com disartria espástica, devido à paralisa cerebral e onze crianças sem alterações de fala. As crianças foram solicitadas a repetir, tão rápido quanto possível, as emissões /pa/, /ta/, /fa/, /sa/, /xa/, /taka/, /kaka/, /pataka/ e /fasaxa/ e foram realizados cálculos sobre a duração silábica da emissão 
gravada pelo programa Speech Lab. O grupo de disartria espástica obteve um escore inferior quando comparado ao grupo de crianças sem alterações de fala, em todas as tarefas, com exceção da relação s/z e da razão da duração silábica nas emissões trissílabas, dividido pela duração silábica nas emissões monossílabas. Na tarefa da DDC as crianças com disartria apresentaram durações silábicas maiores e mais variadas quando comparado às crianças sem alterações de fala. Embora tenha havido grande variabilidade intra e intersujeitos em ambos os grupos estudados, considerou-se que as tarefas avaliadas contribuem no diagnóstico da disartria espástica.

WOLK; EDWARDS; CONTURE ${ }^{66}$, 1993, avaliaram a fluência, a fonologia e a DDC em 21 crianças de quatro anos e dois meses a cinco anos e onze meses de idade, divididas em três grupos: crianças que apresentavam gagueira e habilidade fonológica adequada; gagueira e distúrbio fonológico; fluência adequada e distúrbio fonológico. Foram utilizadas as tarefas de fala espontânea, de nomeação de figura e de DDC, sendo que, para esta última, as crianças foram solicitadas a produzir oito seqüências de sons, sendo quatro surdas: /papa/, /pata/; /taka/; e /pataka/ e quatro sonoras: /baba/, /bada/; /daga/; /badaga/. Para determinar a taxa da DDC, foram excluídos os trechos de disfluência e de erros fonológicos. Não foram encontradas diferenças significantes entre os grupos para as produções dissílabas e trissílabas e entre emissões surdas e sonoras, durante a tarefa da DDC.

WIT et al. ${ }^{64}, 1994$, investigaram a influência da aquisição de fala nas habilidades motoras da fala de crianças com disartria espástica, sendo duas devido a traumatismo crânio-encefálico e duas adquiridas no período perinatal. Também foram avaliadas cinco crianças com disartria espástica, constituindo um grupo de referência e ainda cinco meninos sem distúrbio de fala, formando um grupo controle. Avaliou-se o tempo máximo de fonação e a freqüência fundamental, além da DDC, considerando-se a taxa, regularidade e precisão das seguintes monossílabas: /pa/; /ta/ e /ka/. A prova mais rápida e mais correta dentre três para cada sílaba foi analisada utilizando-se Speech Lab. Foram encontradas diferenças entre os desempenhos dos grupos de crianças quanto às diversas tarefas. Os autores verificaram que o grupo de referência disártrico apresentou emissões mais curtas nas tarefas de tempo máximo de fonação; menor extensão da freqüência fundamental e durações silábicas mais 
longas, quando comparado ao grupo controle. As duas crianças com trauma cerebral realizaram o tempo máximo de fonação e extensão da freqüência fundamental dentro do limite normal, mas a duração silábica foi extremamente longa; as duas crianças com disartria adquirida no período perinatal foram piores que seus correspondentes sem distúrbio de fala, nas tarefas de tempo máximo de fonação, extensão da freqüência fundamental e DDC. Os autores referiram que estes resultados evidenciaram diferentes perfis motores de fala, em relação ao grupo com traumatismo e com paralisia cerebral e concluíram que as tarefas de máximo desempenho podem ser utilizadas para descobrir diferenças nas manifestações da condição patofisiológica na criança com disartria espástica.

TOWNE $^{58}$, 1994, comparou a habilidade compensatória dos movimentos de língua na situação em que a mandíbula encontrava-se estabilizada por uma placa de mordida, em quinze crianças com média de idade de cinco anos que apresentavam habilidade fonológica adequada, ou problemas articulatórios leves, e em outras quinze crianças com média de idade de quatro anos e onze meses que apresentavam alterações fonológicas mais acentuadas. A avaliação da DDC foi aplicada nas situações em que a mandíbula permaneceu livre e quando a mandíbula apresentava-se estabilizada por uma placa. Três provas foram registradas para as seqüências $/ \mathrm{t} \wedge / \mathrm{k} / \mathrm{k} \wedge / \mathrm{e} / \mathrm{t} \wedge \mathrm{k} \wedge /$. As provas foram analisadas durante $\mathrm{o}$ tempo de cinco segundos, por meio da onda de fala registrada em um osciloscópio. Para fins de análise do máximo desempenho e da habilidade compensatória, considerou-se a seqüência produzida mais rápido. A taxa da DDC, para as crianças com distúrbio fonológico, foi significativamente mais lenta comparada às crianças sem distúrbio fonológico, sendo que, em ambos os grupos, a taxa da DDC foi mais lenta na condição em que a mandíbula estava estabilizada.

THOONEN et al. ${ }^{56}, 1996$, utilizaram tarefas de máximo desempenho para diagnóstico diferencial em crianças com distúrbio motor da fala. Avaliaram nove crianças com apraxia do desenvolvimento da fala, onze crianças com disartria espástica e um grupo controle de onze crianças sem problemas de aprendizagem, sem história de problemas auditivos, da fala e linguagem, ou anormalidades estruturais que limitassem a fala. Foi verificado o tempo máximo de fonação da vogal /a/, da seqüência /mama/ e das fricativas /f/,/s/ e /z/, assim 
como utilizado a DDC e as seqüências monossílabas /pa/, /ta/ e /ka/ e da trissílaba /pataka/. Foram realizadas três produções para cada seqüência e escolhida a mais rápida e a mais correta para análise, a partir de um oscilograma (Speech Lab). A DDC foi calculada pelo número de repetições por segundo. Os achados mostraram que crianças com disartria espástica puderam ser diferenciadas das crianças com apraxia do desenvolvimento da fala e das crianças do grupo controle, somente na taxa de repetição monossilábica e no tempo máximo da vogal. As crianças com apraxia do desenvolvimento da fala diferiram das crianças falantes normais, no tempo máximo de fonação das fricativas, na taxa de repetição trissilábica e no desempenho de repetição trissilábica, bem como no número de erros seqüenciais e no número de tentativas. Os autores concluíram que a combinação das medidas das tarefas de máximo desempenho contribui de maneira importante para o diagnóstico do distúrbio de fala, tanto quanto para a diferenciação da disartria e apraxia.

COHEN; WATERS; HEWLETT ${ }^{12}$, 1998, sugeriram um protocolo detalhado para mensurar e analisar a DDC, devido à existência de grande variação quanto aos métodos de investigação descritos na literatura. Este novo método foi aplicado em um estudo-piloto, composto de quatorze crianças com o desenvolvimento adequado, com idades variando entre três anos e dez meses a quatro anos e onze meses, e catorze crianças com distúrbio fonológico, com idades de três anos e oito meses a cinco anos e três meses.

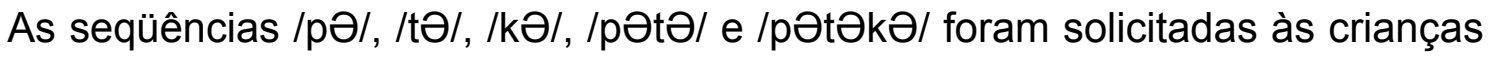
com o apoio lúdico de um trem, sendo somente as seqüências precisamente produzidas utilizadas na análise espectrográfica. A primeira e a última sílabas foram excluídas da análise, sendo verificado o número de sílabas por segundo. De acordo com os autores, a transcrição perceptiva, em conjunto com a análise acústica, permite avaliar a precisão e a consistência das crianças nas tarefas da DDC, e comparar estes achados com os erros encontrados durante as tarefas de fala espontânea e imitação, sugerindo que a análise dos erros, evidentes nas tarefas da DDC (particularmente erros na seqüência polissilábica), mas não evidentes durante a fala espontânea, pode revelar a limitação da capacidade de controle motor oral da criança, mais efetivamente que as medidas da taxa isoladamente. Os autores concluíram que somente 
quando houver maior consistência do método na coleta e análise dos dados, é que a utilidade clínica da DDC pode ser explorada completamente.

WILLIAMS; STACKHOUSE ${ }^{61}$, 1998, examinaram o desenvolvimento das habilidades da DDC em trinta crianças, com idades entre três e cinco anos, sem histórico e/ou dificuldades atuais de fala, linguagem ou audição e, posteriormente, compararam estes resultados com três casos, com idade variando de quatro a oito anos, com dificuldades específicas da fala. Para a avaliação da DDC, foi medido o tempo de repetição de palavra com e sem significado, e o tempo de repetição de seqüência silábica. Foi analisada a precisão, a consistência e o tempo médio em segundos, para produzir cinco repetições de cada dissílaba e trissílaba. Os autores encontraram melhora na precisão e na consistência das respostas com o aumento da idade, o que não foi observado para o tempo de repetição de sílabas. As crianças do estudo de caso não somente tiveram performance diferente ao do grupo controle, em algumas das medidas, mas também realizaram a performance de forma diferente entre si. Em relação aos três estudos de caso: o primeiro, conforme o esperado na dispraxia verbal do desenvolvimento, apresentou dificuldade na precisão e na consistência da DDC; o segundo, com prejuízo fonológico, apresentou dificuldade na precisão da DDC; o terceiro, com ambas características, disártrica e dispráxica, apresentou dificuldade na taxa, na consistência e na precisão. Embora as três crianças fossem similares quanto à severidade da dificuldade de fala, elas apresentavam padrões diferentes nas tarefas da DDC, distinguindo-as.

THOONEN et al. $^{57}$, 1999, realizaram validação cruzada do procedimento diagnóstico proposto por THONEEN et al. ${ }^{56}, 1996$. O grupo de validação foi composto por dez crianças com apraxia do desenvolvimento da fala; nove crianças com disartria espástica e onze sem distúrbios da fala, com idade variando entre quatro e doze anos. Avaliaram o tempo máximo de fonação e a DDC, conforme proposta de THONEEN et al. ${ }^{56}, 1996$. A DDC do /pa/, /ta/ e /ka/, associada ao tempo máximo de fonação da vogal auxiliaram o diagnóstico da disartria espástica. Já a DDC do /pataka/, associada ao tempo máximo de fonação das fricativas, auxiliaram o diagnóstico de apraxia do desenvolvimento da fala. 
WILLIAMS; STACKHOUSE ${ }^{62}, 2000$, investigaram o desempenho de trinta crianças com desenvolvimento normal, sem histórico ou dificuldade em relação à fala, linguagem ou audição, com idades entre três e cinco anos, quanto aos movimentos orais e às tarefas da DDC silenciosa e da fala. Os movimentos orais envolviam a produção voluntária de movimentos isolados de lábios e língua. Em relação à DDC silenciosa, foram solicitados movimentos seqüenciais de lábios e língua. A DDC da fala foi testada por meio de repetição de palavras com e sem significado e repetição de seqüência silábica, sendo analisado o tempo em segundos para se produzir cinco repetições de palavras dissílabas e trissílabas, além da consistência e precisão. Os resultados demonstraram que todas as crianças levaram um tempo significativamente menor para repetir as palavras dissílabas por cinco vezes do que as palavras trissílabas, e foi verificado um aumento na velocidade de acordo com a idade, para ambas as palavras de duas e três sílabas.

BRASOLOTTO; BEHLAU ${ }^{7}, 2001$, avaliaram vinte crianças de sete anos e um mês a nove anos e seis meses, sendo que dez crianças apresentavam trocas entre sons sonoros e surdos na fala, e dez crianças que não apresentavam trocas. Foi realizada análise acústica computadorizada de voz e análise quantitativa e qualitativa da DDC oral. Para registro e análise das emissões, foi utilizado o programa computadorizado Dr. Speech. Para a DDC, foi solicitada a emissão das seqüências silábicas /a/, /pa/, /ta/, /ka/, /fa/,/sa/, /Jal, /ba/, /dal, /gal, /val, /zal, /3al, /pabal, /tadal, /kaga/, /fava/, /sazal, IJa3a/, /pataka/, /badaga/, /fasala/, /vaza3a/, por oito segundos cada. O grupo de crianças que realizava trocas de sonoridade apresentou menor número de emissões de /za/ e /vaza3a/. Em relação à análise qualitativa da DDC, não foram encontradas diferenças significantes entre os dois grupos, porém as crianças com alteração na fala realizaram mais repetições arrítmicas de $/ \mathrm{ka} /$. Os resultados indicaram que as crianças avaliadas que trocavam sons sonoros e surdos apresentavam dificuldades de controle motor oral e glótico.

FAWCETT; NICOLSON ${ }^{19}$, 2002, estudaram a velocidade de produção de gestos articulatórios simples em dois grupos de crianças com dislexia, com média de idade de treze e dezesseis anos e em outros dois 
grupos de crianças sem dislexia. Nenhuma das crianças tinha qualquer outro problema na fala ou na articulação, como ceceio ou disfluência. Em relação à DDC, foi utilizada a repetição de /p/, /t, e /k/ e /ptk/. Duas análises foram feitas: a duração articulatória do primeiro gesto, excluindo a pausa interarticulatória, e o tempo médio de duração dos cinco primeiros gestos, incluindo as pausas interarticulatórias. Em relação à DDC, as crianças com dislexia foram mais lentas quando comparadas ao grupo controle de idade correspondente; o efeito da idade não foi significante. O déficit foi maior na duração do gesto que na duração articulatória, uma vez que a duração do gesto foi de 30 a 50\% mais longa que o tempo articulatório básico, nas crianças com dislexia

YARUSS; LOGAN ${ }^{67}$, 2002, buscaram explorar a possibilidade de que a avaliação da fluência e da precisão das produções da DDC em crianças pode fornecer um suplemento significativo para as medidas tradicionais da DDC. Foram avaliados quinze meninos, com idades entre três e sete anos, sem alterações de fala, linguagem ou audição. Eles foram conduzidos a produzir dez repetições das sílabas "puh-tuh-kuh" ou "pattycake". As seguintes análises foram realizadas: número de emissões por segundo, incluindo as emissões que continham erros articulatórios e disfluências; número de emissões por segundo das emissões precisas e fluentes; número e tipos de erros articulatórios e de disfluências produzidos durante todas as provas da DDC. De acordo com os resultados, as crianças produziram erros articulatórios freqüentes, mas poucas disfluências durante tarefas da DDC; nenhuma correlação significante foi encontrada entre a idade cronológica e o número médio de erros articulatórios ou disfluência na avaliação da DDC; houve correlação entre a idade e o número de emissões por segundo, incluindo as emissões que continham erros articulatórios ou disfluências, entretanto, nenhuma correlação significante foi encontrada entre a idade cronológica e a taxa da DDC, para interações precisas e fluentes. Os autores concluíram que os erros e as disfluências não afetaram a taxa da DDC.

PRATHANEE; THANAVIRATANANICH; PONGJANYAKUL ${ }^{46}, 2003$, realizaram um estudo visando estabelecer parâmetros para avaliação, diagnóstico e tratamento de pacientes com alteração na função-motora oral. Foram avaliados 142 crianças tailandesas, com idades entre seis e treze anos, com função e estrutura do mecanismo oral adequadas. Foi realizado o teste da 
DDC oral, por meio das seguintes repetições de fala: /pə/, /a:-u:/, /u:-i:/, li:-a:/, /tӘ/, //Ә/, /kӘ/, /tӘ-kӘ/, /pӘ-tӘ/, /pӘ-kӘ/, /pӘ-tӘ-kӘ/ e estalar a língua e da seguinte repetição silenciosa: lateralizar a língua tocando as comissuras labiais. Para o cálculo da taxa da DDC, foram solicitadas vinte repetições de monossílabas, quinze dissílabas e dez trissílabas. Para o cálculo do tempo médio de produção destes sons, utilizou-se o Visi Pitch ${ }^{\circledR}$. O tempo dos movimentos silenciosos foi mensurado por meio do apoio visual e com a utilização de um cronômetro, e o tempo transcorrido para o estalo de língua foi mensurado por meio do apoio auditivo e pelo uso do cronômetro. Os resultados demonstraram que o tempo requisitado para a DDC diminuiu significantemente com a idade; foi significante a diferença entre os meninos e as meninas durante as emissões de /pӘ/; /tӘ/, /kӘ/, estalo e lateralização da língua. De forma geral, meninos tenderam a ser mais rápidos do que as meninas.

LEWIS et al. ${ }^{33}, 2004$, acompanharam, durante a idade pré-escolar até à idade escolar, sete meninos e três meninas com diagnóstico de apraxia da fala. Essas crianças foram comparadas a dois outros grupos, um que apresentava distúrbio isolado dos sons da fala, composto por sete meninos e oito meninas, e outro, com distúrbio de fala e linguagem, composto de cinco meninas e nove meninos. Todas as crianças apresentavam inteligência e acuidade auditiva adequadas e não apresentavam distúrbios neurológicos. Foram realizadas avaliações de articulação, linguagem, leitura, soletração e DDC, essa última avaliada por meio das repetições das monossílabas $(\mathrm{p} \wedge, \mathrm{t} \wedge$, $\mathrm{k} \wedge, \mathrm{f} \wedge, \mathrm{I} \wedge$ ), das dissílabas $(\mathrm{p} \wedge \mathrm{t} \partial, \mathrm{p} \wedge \mathrm{k} \partial, \mathrm{t} \wedge \mathrm{k} \partial)$ e da trissílaba $(\mathrm{p} \wedge \mathrm{t} \partial \mathrm{k} \partial)$. As crianças também foram solicitadas a repetir vinte palavras com e sem significado. Os autores encontraram que, embora a habilidade articulatória tenha melhorado com a idade escolar, todas as crianças apresentaram erros durante a conversa espontânea; as crianças com apraxia demonstraram pouca melhora na seqüência silábica, tanto em palavras com significado, quanto em palavras sem significado, assim como na repetição de palavras multissilábicas, na repetição de palavras sem significado e na tarefa da DDC. 
3 - MATERIAL E MÉTODO 


\section{MATERIAL E MÉTODO}

\subsection{Aspectos Éticos}

Primeiramente, as Diretoras das Escolas, as quais as crianças pertenciam, foram esclarecidas quanto ao objetivo do estudo e sua aceitação em participar foi expressa pela concordância do Termo de Aquiescência (Anexos 1 e 2). Os responsáveis pelas crianças foram esclarecidos sobre os objetivos do estudo, a partir da leitura da Carta de Informação ao Sujeito da Pesquisa, sendo que sua concordância foi expressa pela assinatura do Termo de Consentimento Livre e Esclarecido (Anexo 3).

Foram respeitados todos os princípios éticos que versam as Resoluções 196/96 e 257/97 sobre Ética em pesquisa com seres humanos e orientações do Comitê de Ética em Pesquisa da FOB - Faculdade de Odontologia de Bauru - USP, ocorrendo a aprovação do Projeto, no dia 30 de novembro de 2005, por esse Comitê, com processo número 127/2005 (Apêndice 1).

\subsection{Casuística}

O estudo foi realizado com 150 crianças de oito a dez anos de idade, divididas em três faixas etárias: oito, nove e dez anos de idade, sendo 25 do gênero feminino e 25 do gênero masculino. As crianças eram provenientes de duas escolas públicas estaduais do Ensino Fundamental da cidade de Bauru, sendo uma das escolas freqüentadas por alunos pertencentes ao nível sócioeconômico médio inferior e a outra, ao nível médio.

As crianças de oito, nove e dez anos apresentaram médias de idades, respectivamente:

- $101 ; 112,72 ; 126,2$ meses para o gênero feminino;

- 102,$4 ; 113,4 ; 125,2$ meses para o gênero masculino. 


\subsubsection{Seleção da amostra}

Foi entregue aos responsáveis pelas crianças, um questionário (Anexo 4) composto de questões referentes à saúde geral e sobre hábitos vocais, com o intuito de caracterizar a população, bem como, de auxiliar no critério de exclusão. Foram adotados os seguintes critérios de exclusão, demonstrados de forma progressiva, de acordo com o andamento do trabalho.

Primeiramente, quando os responsáveis indicavam no questionário que as crianças apresentavam história de problemas neurológicos e/ou doenças respiratórias baixas, as crianças imediatamente eram excluídas.

O primeiro contato com as crianças, cujos responsáveis não indicaram fatores de exclusão no questionário, foi realizado por meio de uma conversa espontânea. As crianças que apresentavam, no dia da avaliação, sinais de obstrução nasal ou qualquer estado que prejudicasse a disposição para a execução dos testes, foram excluídas. A presença de aparelho ortodôntico foi englobada neste item, quando este pudesse interferir nos demais procedimentos. Além disso, se durante a conversa com a avaliadora, a criança apresentasse rugosidade na voz de grau 2 ou superior (HIRANO ${ }^{26}$, 1981), os demais procedimentos não seriam realizados. As crianças não excluídas por esses fatores foram submetidas à gravação de um trecho de conversa espontânea, contagem de um a dez, além de uma emissão sustentada da vogal "a". Na seqüência, foi aplicada a cada criança a prova de nomeação, referente à parte A do Teste ABFW (ANDRADE et.al, ${ }^{3} 2004$ ), que é composto por 34 figuras, a fim de verificar a ocorrência de alterações fonéticofonológicas, seguindo os critérios adotados por WERTZNER, ${ }^{59} 2004$.

Após o levantamento do inventário fonético por meio deste instrumento foi realizada a análise tradicional e dos processos fonológicos. $O$ critério de exclusão, baseado no proposto por WERTZNER ${ }^{59}, 2004$, na análise tradicional, considera como inadequados, os fonemas produzidos com menos de $75 \%$ de acertos. Foram excluídas da amostra as crianças que apresentavam alterações no inventário fonético, tais como, substituição e distorção, sendo considerados distorções o ceceio e/ou a produção imprecisa de fonemas, e a substituição foi relacionada à troca de um fonema por outro, sendo esta produtiva ou não, uma vez que a análise por processos fonológicos 
considera a produtividade desses. Cada processo é considerado produtivo se aparecer em mais de $25 \%$ de suas possibilidades de ocorrência. Foram excluídas também crianças que apresentavam quadro de disfluência. Duas juízas, fonoaudiólogas, incluindo a autora, participaram destas análises, havendo $100 \%$ de concordância.

Ressalte-se que as crianças que apresentaram rugosidade na voz de grau 2 ou superior $\left(\right.$ HIRANO $\left.^{26}, 1981\right)$ já haviam sido excluídas pela análise perceptivo-auditiva da voz, realizada pela avaliadora. Mesmo assim, a fim de verificar a concordância da análise perceptivo-auditiva, três fonoaudiólogos, especialistas em voz, realizaram análise perceptivo-auditiva a partir dos trechos de fala gravados (conversa espontânea, contagem de um a dez e emissão da vogal sustentada "a") das 150 crianças incluídas. Caso as crianças fossem consideradas portadoras de voz rugosa em grau 2 (moderado), ou superior por dois ou três juízes, seriam excluídas. Nenhuma das crianças foi excluída por esse critério, sendo assim, houve $100 \%$ de concordância entre a avaliadora e os juízes.

Após a delimitação da amostra, esta foi caracterizada por meio dos resultados das respostas do questionário entregue aos pais ou responsáveis (Anexo 5).

\subsection{Gravação das emissões para avaliação da DDC}

As gravações foram realizadas nas dependências das Escolas, em sala, com o menor ruído possível (menor que $50 \mathrm{~dB}$ ), utilizando-se gravador digital, marca "SONY", modelo MZN510. As crianças permaneceram sentadas e o microfone de cabeça, marca AKG, modelo C444PP, foi posicionado lateralmente a 60 graus e a dez $\mathrm{cm}$ da comissura labial. $O$ microfone de cabeça foi adaptado a uma mesa de som, marca Behringer, Modelo UB 802, versão 1.2, a fim de proporcionar maior ganho de intensidade. $O$ gravador digital foi alimentado por energia proveniente de bateria, e a mesa de som foi acoplada a um estabilizador de voltagem, marca APC Line- $R^{T M}$, modelo LE300-BR. Ambos procedimentos foram adotados para se evitar interferência de possíveis variações de energia e interferências elétricas durante as gravações. 
Foi realizada a avaliação da DDC oral e laríngea, por meio da repetição das sílabas "pa", "ta", "ca" e "pataca", bem como das vogais "a" e "i".

Cada emissão foi gravada durante seis segundos. Considerando-se que as emissões silábicas isoladas de "pa", "ta" e "ca" devam ser mais fáceis do que a seqüência "pataca", ou do que a repetição de vogais. Vale ressaltar que a emissão da trissílaba "pataca" era acentuada na última sílaba, foram solicitadas, inicialmente, as monossílabas, depois a trissílaba "pataca", seguida das vogais "a", "i". Para evitar que a primeira produção tivesse desempenho diferente das demais, a ordem de solicitação das três sílabas ("pa", "ta" ou "ca") foi variada a partir da distribuição aleatória das seis combinações possíveis entre essas emissões.

Antes de iniciar as emissões, o avaliador realizou orientações e treinamento de como se repetir o som tão rápido quanto possível, por um tempo determinado. Cada criança teve a chance de treinar os sons, quantas vezes fossem necessárias, antes de cada gravação, em sucessão rápida e mantendo a articulação clara e precisa utilizando durante as emissões, altura e intensidade de voz confortáveis, até que a criança compreendesse a forma de execução da prova. Posteriormente, a criança foi instruída a "manter a produção tão rápida quanto possível" durante o tempo em que a avaliadora permanecesse com o braço erguido. Depois de realizado o treino, cada emissão foi gravada de duas a três vezes, a fim de certificar a correta gravação.

\subsection{Edição das gravações das emissões "pa”, "ta”, “ca”, “pataca”, "a” e} “i”

Após a coleta das emissões, todas as amostras gravadas foram transportadas do Minidisc Deck MDS-JE320, Sony, por meio de um cabo RCA para o computador Intel Pentium (R) 4, CPU $2.040 \mathrm{GHz}$ e $256 \mathrm{MB}$ de RAM, monitor LG Flatron E7015 17, placa de som modelo Audigy II, marca Creative, do Laboratório de Voz da Clínica de Fonoaudiologia da Faculdade de Odontologia de Bauru/USP. As emissões foram gravadas no computador por meio de um software de edição de áudio profissional, Sound Forge 7.0, em taxa de amostragem de $44.100 \mathrm{~Hz}$, canal Mono em 16 bit. Para posterior 
análise, as mesmas amostras foram arquivadas, utilizando-se a taxa de amostragem de $11.025 \mathrm{~Hz}$.

Para a edição das gravações das seqüências monossilábicas e das vogais, a primeira gravação de cada emissão foi utilizada para a análise da DDC, sendo excluídos os dois primeiros e o último segundo da amostra, e considerado o número de emissões realizadas nesse intervalo de tempo. Caso a primeira gravação não estivesse em condições de análise, a segunda seria utilizada e assim sucessivamente.

No tempo de análise de três segundos, se o cursor estivesse posicionado em cima da emissão, em decorrência da exclusão dos segundos iniciais e finais da amostra, foi adotado o seguinte procedimento: se o corte do início interrompesse uma emissão, o cursor era retrocedido ao início da emissão, sendo contados os três segundos para análise a partir desse ponto; se o corte do trecho final coincidisse com uma emissão, essa seria computada no tempo de análise.

Para a edição da seqüência "pataca" foram utilizadas para análise, as emissões produzidas corretamente, de forma clara e precisa. Caso a criança não conseguisse essas condições, mesmo após treinamento, não seria computado o resultado da emissão para esse participante.

Para a análise das emissões "pataca" foram excluídos os dois primeiros segundos da amostra, sendo adotado o seguinte procedimento: durante o corte dos dois segundos iniciais, se o cursor interrompesse uma emissão, este seria retrocedido até o início da emissão. Ressalta-se que se o corte dos dois segundos iniciais atingisse um espaço de tempo entre uma emissão e outra, o cursor também seria deslocado para o início da emissão. A partir do início da emissão, o cursor percorreu o tempo de três segundos mais o tempo necessário, até alcançar o ponto antes do início da outra emissão "pataca". Sendo assim, apenas para a emissão "pataca" o tempo de análise foi um pouco maior em décimos de segundo, ou em até um segundo a mais do que as emissões monossilábicas. Para o cálculo da taxa da DDC foi considerado o número de emissões por segundo. Em um exemplo, em que o cursor teve que ser deslocado até 3,29 segundos para incluir ciclos completos da emissão, a criança realizou seis emissões da seqüência "pataca", o que resultou em 1,82 emissões por segundo. 


\subsection{Análise da DDC oral e laríngea}

A DDC da seqüência "pataca" foi analisada quantitativamente, por meio do programa computadorizado Mult Speech Main Program, Modelo 3700 , versão 2.5.2 da Kay Elemetrics Corp, utilizando taxa de amostragem em $11.025 \mathrm{~Hz}$ na análise espectrográfica. A contagem do número de seqüências trissilábicas por segundo foi realizada pela avaliadora de forma manual, com o apoio da pista visual e auditiva, após ser demarcado o tempo a ser analisado (Figura 1).

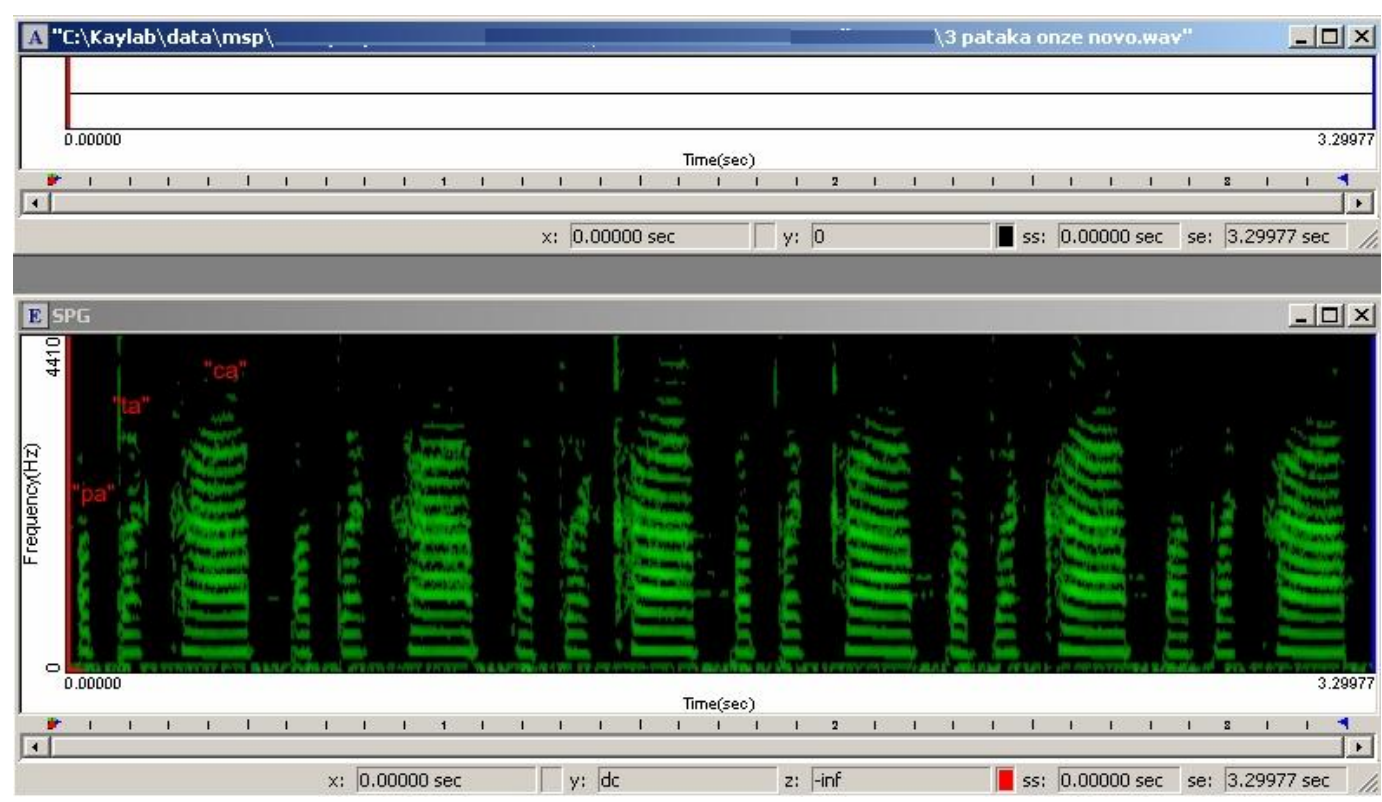

Figura 1: Espectrograma da emissão da seqüência "pataca", no qual se podem observar seis trissílabas no tempo de análise de 3.29 segundos

A análise das monossílabas "pa", "ta" e "ca" e das vogais "a", "i" foi realizada por meio do programa Motor Speech Profile Advanced (MSP), Modelo 5141, versão 2.5.2 da Kay Elemetrics Corp., sendo considerada, no ajuste de captura, a taxa de amostragem de $11.025 \mathrm{~Hz}$.

O programa MSP apresenta um registro gráfico das emissões, apresentando, no eixo horizontal, o tempo em segundos e no eixo vertical, a energia em dB (Figura 2). Para realizar as contagens da DDC, o programa traça uma linha no ponto central na escala de energia em $\mathrm{dB}$ do eixo vertical. $\mathrm{O}$ valor utilizado para delimitar o ponto foi o valor da Intensidade Média da 
amostra da DDC (DDKava), fornecido pelo próprio programa MSP, durante a análise em cada emissão.

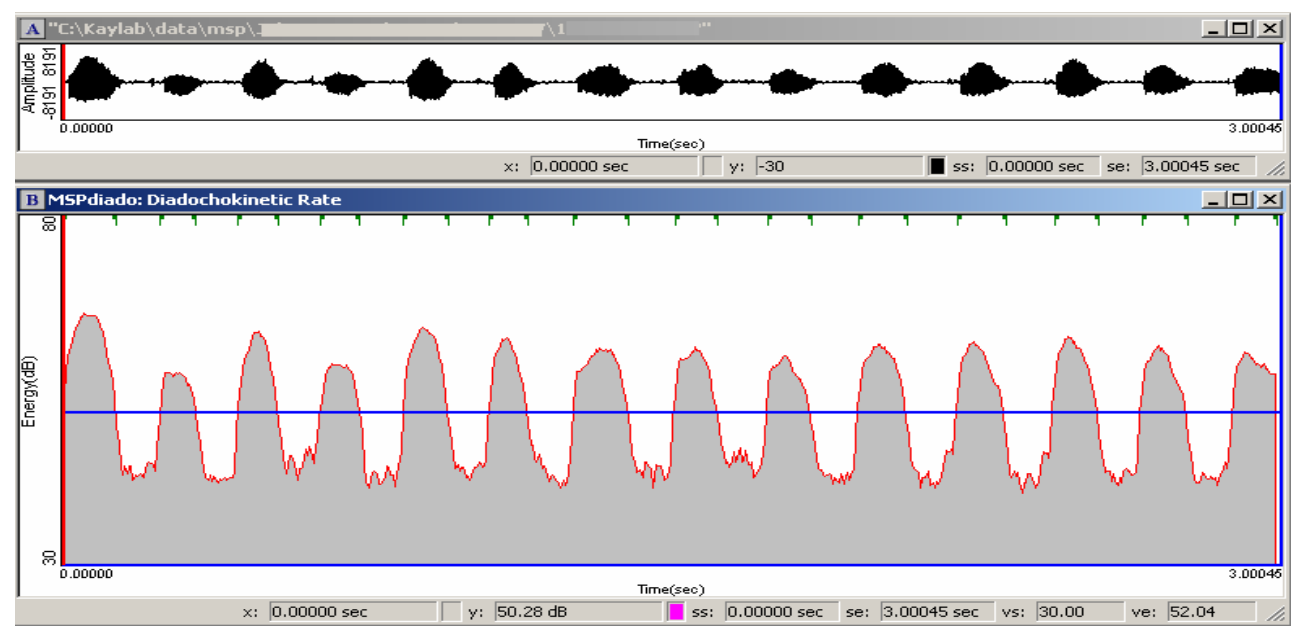

Figura 2: Gráfico do programa MSP na qual se observa o tempo (segundos) no eixo horizontal e a energia (dB) no eixo vertical

Algumas emissões produziram um gráfico contendo instabilidades nos contornos de energia. Desta forma, dependendo da posição da linha de análise o programa contava duas vezes uma mesma sílaba. Para esses casos padronizou-se que a linha de análise deveria ser rebaixada ou elevada, a fim de não computar estes subpicos (Figura 3).

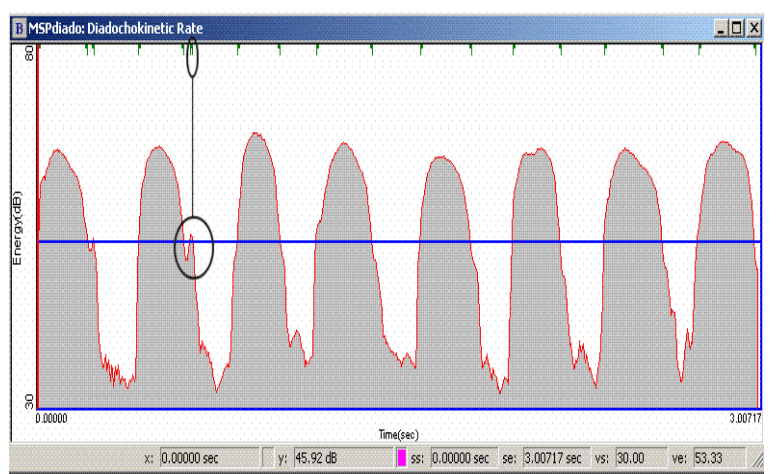

3 a

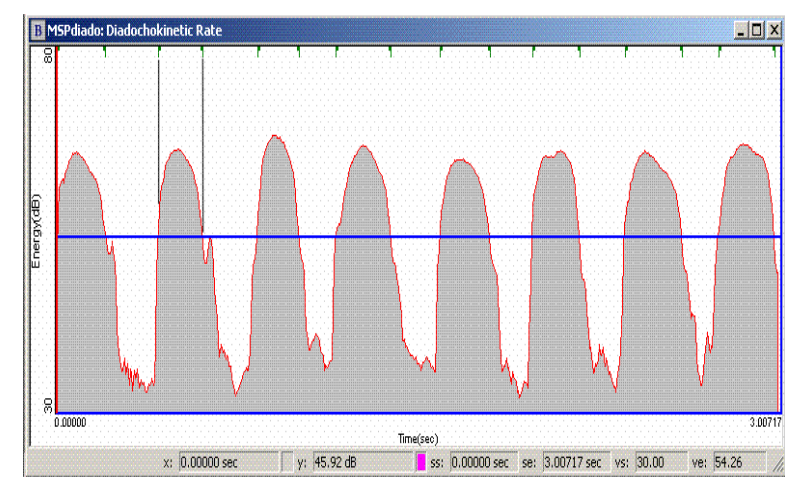

$3 \mathbf{b}$

Figura 3: Linha de análise coincidindo com ponto de instabilidade e resultando na contagem de subpicos ( 3 a); Linha de análise elevada para não computar subpicos (3 b). 
Os parâmetros da DDC monossilábica são fornecidos automaticamente pelo programa MSP (Figura 4)

\begin{tabular}{l|c|l}
\hline \multicolumn{1}{c|}{ Parâmetros } & Unidade & \multicolumn{1}{c}{ Observações } \\
\hline Média da taxa da DDC (mT) & /s/ & $\begin{array}{l}\text { Número de vocalizações por segundo, que } \\
\text { representa a velocidade de DDC }\end{array}$ \\
\hline Média do período da DDC (mP) & Ms & Tempo médio entre as vocalizações \\
\hline $\begin{array}{l}\text { Desvio-padrão do período da } \\
\text { DDC (dpP) }\end{array}$ & Ms & \\
\hline $\begin{array}{l}\text { Coeficiente de variação do } \\
\text { período da DDC (cvP) }\end{array}$ & $\%$ & $\begin{array}{l}\text { Mede o grau de variação da taxa no } \\
\text { período, indicando a habilidade em manter } \\
\text { uma taxa de vocalizações constante. }\end{array}$ \\
\hline $\begin{array}{l}\text { Perturbações do período da DDC } \\
\text { (jitP) }\end{array}$ & $\%$ & $\begin{array}{l}\text { Mede o grau de variação, ciclo-a-ciclo, no } \\
\text { período, indicando a habilidade em manter } \\
\text { uma taxa de vocalizações constante. }\end{array}$ \\
\hline $\begin{array}{l}\text { Coeficiente de variação do pico } \\
\text { da intensidade da DDC (cvl) }\end{array}$ & $\%$ & $\begin{array}{l}\text { Mede o grau de variação da intensidade no } \\
\text { pico de cada vocalização, indicando a } \\
\text { habilidade em manter constante a } \\
\text { intensidade das vocalizações. }\end{array}$ \\
\hline
\end{tabular}

Figura 4: Parâmetros analisados para DDC de emissões monossilábicas

\subsection{Análise Estatística}

Para caracterização dos grupos foram utilizadas média, mediana e percentis dos resultados para cada parâmetro estudado de cada emissão "pa", "ta", "ca”, "pataca”, "a" e "i”. A comparação dos resultados entre os subgrupos de gênero e idade foi realizada por meio da Análise de Variância a dois critérios e quando esta indicou diferença estatisticamente significante, foi utilizado o teste de Tuckey para as comparações individuais. Em todos os testes foi adotado nível de significância de $5 \%$. 
4 - RESULTADOS 


\section{RESULTADOS}

A caracterização dos grupos em relação aos resultados da DDC oral e laríngea para as sílabas "pa", "ta", "ca", para a trissílaba "pataca" e para as vogais "a" e "i", estão demonstrados nas tabelas de 1 a 12, nas quais constam os valores da média, desvio-padrão, mediana e percentis, referentes aos valores da média da taxa da DDC $(\mathrm{mT})$, da média do período da DDC (mP), do desvio-padrão do período da DDC (dpP), do coeficiente de variação do período da DDC (cvP), da perturbação em jitter do período da DDC (jitP), além do coeficiente de variação do pico da intensidade da DDC (cvl).

Os valores das médias da DDC oral e laríngea por idade e por gênero estão apresentados, por emissão, nas tabelas 13, 15, 17, 19, 21 e 23.

As tabelas 14, 16, 18, 20, 22 e 24 demonstram a comparação dos resultados da DDC entre os subgrupos de gênero e idade para cada uma das emissões.

Os subgrupos de meninos e meninas em cada faixa etária era composto de 25 crianças cada, entretanto, as emissões de "pataca" dos subgrupos de oito anos feminino e masculino e do subgrupo de nove anos feminino, foram produzidas corretamente por 24 crianças. Para o subgrupo de dez anos masculino, as emissões foram produzidas corretamente por 22 crianças. 
Tabela 1: Valores da DDC oral de crianças de oito anos do gênero feminino durante as emissões "pa", "ta", "ca" e "pataca"

\begin{tabular}{|c|c|c|c|c|}
\hline Parâmetros & $\begin{array}{c}\text { Média } \\
\pm \text { desvio padrão }\end{array}$ & Mediana & $\begin{array}{l}\text { Percentil } \\
\quad 2,5\end{array}$ & $\begin{array}{l}\text { Percentil } \\
\quad 97,5\end{array}$ \\
\hline mT "pa" (Is) & $4,77( \pm 0,75)$ & 4,69 & 3,22 & 6,46 \\
\hline mT "ta" (Is) & $4,97( \pm 0,79)$ & 4,95 & 3,34 & 6,80 \\
\hline mT "ca" (/s) & $4,39( \pm 0,71)$ & 4,26 & 3,20 & 6,16 \\
\hline mT "pataca" (Is) & $1,44( \pm 0,36)$ & 1,49 & 0,78 & 1,94 \\
\hline mP "pa" (ms) & $214,67( \pm 35,26)$ & 213,34 & 154,68 & 310,27 \\
\hline mP "ta" (ms) & $206,79( \pm 36,51)$ & 201,88 & 147,10 & 299,29 \\
\hline mP "ca" (ms) & $233,15( \pm 34,78)$ & 234,49 & 162,37 & 312,32 \\
\hline dpP "pa" (ms) & $16,97( \pm 7,58)$ & 15,85 & 6,23 & 38,05 \\
\hline dpP "ta" (ms) & $14,86( \pm 5,68)$ & 13,75 & 7,86 & 28,21 \\
\hline dpP "ca" (ms) & $17,99( \pm 7,05)$ & 17,13 & 6,14 & 36,72 \\
\hline cvP "pa” (\%) & $8,02( \pm 3,74)$ & 7,20 & 3,03 & 17,54 \\
\hline cvP "ta” (\%) & $7,35( \pm 2,98)$ & 6,40 & 3,36 & 14,47 \\
\hline cvP “ca” (\%) & $7,74( \pm 3,04)$ & 7,39 & 3,71 & 16,75 \\
\hline jitP “pa”(\%) & $2,05( \pm 1,03)$ & 1,98 & 0,15 & 4,32 \\
\hline jitP “ta"(\%) & $1,84( \pm 0,73)$ & 1,71 & 0,98 & 4,25 \\
\hline jitP “ca”(\%) & $2,02( \pm 0,83)$ & 1,89 & 0,80 & 4,15 \\
\hline cvl "pa” (\%) & $2,95( \pm 1,26)$ & 2,65 & 1,17 & 6,15 \\
\hline cvl "ta" (\%) & $2,74( \pm 0,95)$ & 2,57 & 1,26 & 4,91 \\
\hline cvl “ca” (\%) & $3,04( \pm 1,28)$ & 3,13 & 0,79 & 5,42 \\
\hline
\end{tabular}

* Resultado referente ao total de 24 crianças 
Tabela 2: Valores da DDC laríngea de crianças de oito anos do gênero feminino durante as emissões "a" $e$ "i"

\begin{tabular}{|c|c|c|c|c|}
\hline Parâmetros & $\begin{array}{c}\text { Média } \\
\pm \text { desvio padrão }\end{array}$ & Mediana & $\begin{array}{l}\text { Percentil } \\
\quad 2,5\end{array}$ & $\begin{array}{l}\text { Percentil } \\
\quad 97,5\end{array}$ \\
\hline mT "a" (Is) & $2,90( \pm 0,36)$ & 2,86 & 2,17 & 3,76 \\
\hline mT "i" (/s) & $2,75( \pm 0,39)$ & 2,76 & 1,97 & 3,31 \\
\hline mP "a" (ms) & $348,46( \pm 43,18)$ & 349,67 & 265,71 & 460,52 \\
\hline mP “i” (ms) & $370,97( \pm 55,79)$ & 362,67 & 302,35 & 508,28 \\
\hline dpP "a" (ms) & $23,24( \pm 10,15)$ & 19,91 & 10,82 & 52,63 \\
\hline dpP “i” (ms) & $29,62( \pm 21,64)$ & 25,16 & 11,26 & 124,92 \\
\hline cvP "a" (\%) & $6,72( \pm 3,00)$ & 5,41 & 3,50 & 14,73 \\
\hline cvP “i” (\%) & $7,85( \pm 4,93)$ & 6,87 & 3,39 & 27,90 \\
\hline jitP “a” (\%) & $2,67( \pm 1,15)$ & 2,29 & 1,39 & 5,51 \\
\hline jitP “i” (\%) & $3,71( \pm 2,44)$ & 3,40 & 1,69 & 14,18 \\
\hline cvl "a" (\%) & $2,96( \pm 1,01)$ & 2,95 & 0,99 & 5,24 \\
\hline cvl “i” (\%) & $2,86( \pm 1,76)$ & 2,45 & 1,14 & 9,82 \\
\hline
\end{tabular}


Tabela 3: Valores da DDC oral de crianças de oito anos do gênero masculino durante as emissões "pa", "ta", "ca" e "pataca"

\begin{tabular}{|c|c|c|c|c|}
\hline Parâmetros & $\begin{array}{c}\text { Média } \\
\pm \text { desvio padrão }\end{array}$ & Mediana & $\begin{array}{c}\text { Percentil } \\
2,5\end{array}$ & $\begin{array}{c}\text { Percentil } \\
97,5\end{array}$ \\
\hline mT “pa" (Is) & $4,92( \pm 0,51)$ & 4,84 & 3,92 & 5,78 \\
\hline mT "ta" (Is) & $4,93( \pm 0,58)$ & 4,80 & 3,78 & 6,04 \\
\hline mT "ca" (/s) & $4,34( \pm 0,72)$ & 4,47 & 2,91 & 5,56 \\
\hline mT "pataca"* (/s) & $1,66( \pm 0,27)$ & 1,63 & 1,22 & 2,45 \\
\hline mP "pa" (ms) & $205,51( \pm 21,47)$ & 206,71 & 172,98 & 254,95 \\
\hline mP "ta" (ms) & $205,37( \pm 24,16)$ & 208,54 & 165,45 & 264,42 \\
\hline mP “ca” (ms) & $236,89( \pm 43,66)$ & 223,62 & 179,99 & 344,07 \\
\hline dpP "pa" (ms) & $14,14( \pm 5,18)$ & 13,33 & 6,90 & 26,98 \\
\hline dpP "ta" (ms) & $16,31( \pm 8,55)$ & 14,03 & 6,04 & 40,91 \\
\hline dpP "ca" (ms) & $18,76( \pm 9,32)$ & 16,83 & 7,64 & 54,39 \\
\hline cvP "pa" (\%) & $6,85( \pm 2,29)$ & 6,69 & 3,87 & 12,17 \\
\hline cvP “ta” (\%) & $7,90( \pm 3,72)$ & 6,74 & 2,73 & 17,82 \\
\hline cvP "ca” (\%) & $7,78( \pm 2,68)$ & 7,63 & 2,80 & 15,82 \\
\hline jitP "pa"(\%) & $1,69( \pm 0,84)$ & 1,46 & 0,80 & 4,11 \\
\hline jitP "ta"(\%) & $1,80( \pm 0,89)$ & 1,65 & 0,49 & 4,46 \\
\hline jitP “ca"(\%) & $2,13( \pm 1,02)$ & 1,91 & 0,78 & 5,03 \\
\hline cvl "pa" (\%) & $2,91( \pm 1,33)$ & 2,48 & 0,98 & 7,15 \\
\hline cvl "ta" (\%) & $2,61( \pm 1,11)$ & 2,41 & 0,93 & 5,47 \\
\hline cvl "ca" (\%) & $2,79( \pm 1,04)$ & 2,62 & 1,17 & 5,37 \\
\hline
\end{tabular}

* Resultado referente ao total de 24 crianças 
Tabela 4: Valores da DDC laríngea de crianças de oito anos do gênero masculino durante as emissões "a" e "i"

\begin{tabular}{|c|c|c|c|c|}
\hline Parâmetros & $\begin{array}{c}\text { Média } \\
\pm \text { desvio padrão }\end{array}$ & Mediana & $\begin{array}{l}\text { Percentil } \\
\quad 2,5\end{array}$ & $\begin{array}{l}\text { Percentil } \\
97,5\end{array}$ \\
\hline mT "a" (/s) & $3,04( \pm 0,51)$ & 3,07 & 2,26 & 4,45 \\
\hline mT “i” (/s) & $3,07( \pm 0,53)$ & 3,00 & 2,33 & 4,52 \\
\hline mP "a" (ms) & $338,50( \pm 53,77)$ & 327,13 & 224,96 & 443,04 \\
\hline mP "i" (ms) & $334,32( \pm 54,09)$ & 332,93 & 221,31 & 429,49 \\
\hline dpP “a" (ms) & $21,67( \pm 9,38)$ & 19,80 & 9,61 & 40,97 \\
\hline dpP “i” (ms) & $24,15( \pm 9,65)$ & 20,64 & 10,63 & 50,55 \\
\hline cvP "a" (\%) & $6,52( \pm 2,94)$ & 5,96 & 2,61 & 13,31 \\
\hline cvP “i” (\%) & $7,23( \pm 2,60)$ & 7,39 & 3,55 & 14,62 \\
\hline jitP "a" (\%) & $2,53( \pm 1,08)$ & 2,47 & 0,98 & 4,96 \\
\hline jitP “i” (\%) & $3,05( \pm 1,21)$ & 2,83 & 1,00 & 5,23 \\
\hline cvl "a" (\%) & $2,36( \pm 0,98)$ & 2,32 & 0,85 & 4,88 \\
\hline cvl “i” (\%) & $2,46( \pm 0,99)$ & 2,36 & 1,21 & 5,11 \\
\hline
\end{tabular}


Tabela 5: Valores da DDC oral de crianças de nove anos do gênero feminino durante as emissões "pa", "ta", "ca" e "pataca"

\begin{tabular}{|c|c|c|c|c|}
\hline Parâmetros & $\begin{array}{c}\text { Média } \\
\pm \text { desvio padrão }\end{array}$ & Mediana & $\begin{array}{l}\text { Percentil } \\
\quad 2,5\end{array}$ & $\begin{array}{l}\text { Percentil } \\
\quad 97,5\end{array}$ \\
\hline mT "pa" (/s) & $5,23( \pm 0,71)$ & 5,06 & 4,34 & 7,35 \\
\hline mT "ta" (Is) & $5,44( \pm 0,51)$ & 5,42 & 4,60 & 6,70 \\
\hline mT “ca” (Is) & $4,74( \pm 0,56)$ & 4,68 & 3,81 & 5,82 \\
\hline mT "pataca" * (Is) & $1,72( \pm 0,21)$ & 1,72 & 1,29 & 2,33 \\
\hline mP "pa" (ms) & $194,34( \pm 23,00)$ & 197,63 & 136,05 & 230,58 \\
\hline mP "ta" (ms) & $185,44( \pm 17,10)$ & 184,57 & 149,25 & 217,27 \\
\hline mP "ca" (ms) & $213,55( \pm 24,88)$ & 213,80 & 171,94 & 262,37 \\
\hline dpP “pa” (ms) & $16,30( \pm 8,34)$ & 14,27 & 7,94 & 46,23 \\
\hline dpP "ta" (ms) & $15,54( \pm 4,79)$ & 14,70 & 9,58 & 26,04 \\
\hline dpP “ca" (ms) & $18,72( \pm 8,51)$ & 16,70 & 8,62 & 51,17 \\
\hline cvP “pa” (\%) & $8,37( \pm 3,92)$ & 7,65 & 3,93 & 20,94 \\
\hline cvP "ta" (\%) & $8,38( \pm 2,41)$ & 8,20 & 4,92 & 14,11 \\
\hline cvP “ca” (\%) & $8,69( \pm 3,31)$ & 7,91 & 3,99 & 19,79 \\
\hline jitP “pa”(\%) & $1,75( \pm 0,71)$ & 1,61 & 0,90 & 4,22 \\
\hline jitP “ta"(\%) & $1,94( \pm 0,82)$ & 1,59 & 1,02 & 3,69 \\
\hline jitP “ca”(\%) & $2,18( \pm 1,23)$ & 1,80 & 0,89 & 6,49 \\
\hline cvl "pa” (\%) & $2,90( \pm 1,11)$ & 2,57 & 1,18 & 5,22 \\
\hline cvl "ta" (\%) & $2,34( \pm 0,79)$ & 2,21 & 1,05 & 3,95 \\
\hline cvl "ca" (\%) & $2,84( \pm 1,10)$ & 2,52 & 1,56 & 5,73 \\
\hline
\end{tabular}

\footnotetext{
* Resultado referente ao total de 24 crianças
} 
Tabela 6: Valores da DDC laríngea de crianças de nove anos do gênero feminino durante as emissões "a" $e$ "i"

\begin{tabular}{|c|c|c|c|c|}
\hline Parâmetros & $\begin{array}{c}\text { Média } \\
\pm \text { desvio padrão }\end{array}$ & Mediana & $\begin{array}{l}\text { Percentil } \\
\quad 2,5\end{array}$ & $\begin{array}{l}\text { Percentil } \\
97,5\end{array}$ \\
\hline $\mathrm{mTa}(/ \mathrm{s})$ & $3,22( \pm 0,66)$ & 3,13 & 2,05 & 5,13 \\
\hline mT "i" (/s) & $3,22( \pm 0,57)$ & 3,24 & 2,24 & 4,49 \\
\hline$m P$ "a" (ms) & $322,21( \pm 63,31)$ & 319,04 & 194,88 & 487,52 \\
\hline mP "i" (ms) & $319,99( \pm 56,88)$ & 308,42 & 222,46 & 447,31 \\
\hline dpP "a" (ms) & $20,15( \pm 6,82)$ & 19,70 & 5,87 & 36,57 \\
\hline dpP “i” (ms) & $22,11( \pm 11,11)$ & 19,60 & 8,23 & 51,90 \\
\hline cvP “a” (\%) & $6,40( \pm 2,21)$ & 6,32 & 1,75 & 11,53 \\
\hline cvP “i” (\%) & $7,29( \pm 4,75)$ & 6,40 & 2,41 & 23,33 \\
\hline jitP “a” (\%) & $2,62( \pm 1,12)$ & 2,39 & 0,72 & 4,89 \\
\hline jitP “i” (\%) & $2,89( \pm 1,54)$ & 2,71 & 0,77 & 8,06 \\
\hline cvl "a" (\%) & $2,54( \pm 1,33)$ & 2,15 & 0,85 & 6,51 \\
\hline cvl “i” (\%) & $2,64( \pm 1,16)$ & 2,54 & 0,92 & 5,82 \\
\hline
\end{tabular}


Tabela 7: Valores da DDC oral de crianças de nove anos do gênero masculino durante as emissões "pa", "ta" "ca" e "pataca"

\begin{tabular}{|c|c|c|c|c|}
\hline Parâmetros & $\begin{array}{c}\text { Média } \\
\pm \text { desvio padrão }\end{array}$ & Mediana & $\begin{array}{l}\text { Percentil } \\
\quad 2,5\end{array}$ & $\begin{array}{c}\text { Percentil } \\
97,5\end{array}$ \\
\hline mT "pa" (Is) & $5,04( \pm 0,48)$ & 5,07 & 3,84 & 5,80 \\
\hline mT "ta" (Is) & $5,05( \pm 0,60)$ & 5,09 & 3,86 & 6,38 \\
\hline mT "ca" (Is) & $4,64( \pm 0,71)$ & 4,63 & 2,68 & 5,73 \\
\hline mT "pataca" (Is) & $1,68( \pm 0,19)$ & 1,70 & 1,17 & 1,99 \\
\hline mP "pa" (ms) & $200,25( \pm 20,29)$ & 197,18 & 172,55 & 260,46 \\
\hline mP “ta" (ms) & $200,65( \pm 24,68)$ & 196,59 & 156,82 & 259,07 \\
\hline mP "ca" (ms) & $221,42( \pm 41,42)$ & 215,83 & 174,41 & 372,56 \\
\hline dpP "pa" (ms) & $15,16( \pm 6,14)$ & 13,92 & 8,14 & 35,56 \\
\hline dpP "ta" (ms) & $18,71( \pm 11,07)$ & 14,12 & 8,49 & 52,10 \\
\hline dpP “ca" (ms) & $17,93( \pm 7,22)$ & 15,75 & 8,14 & 33,10 \\
\hline cvP "pa" (\%) & $7,55( \pm 2,86)$ & 6,90 & 4,27 & 16,16 \\
\hline cvP "ta” (\%) & $9,27( \pm 5,17)$ & 7,43 & 4,07 & 24,94 \\
\hline cvP “ca” (\%) & $8,21( \pm 3,23)$ & 6,97 & 3,60 & 15,41 \\
\hline jitP “pa”(\%) & $1,76( \pm 0,67)$ & 1,64 & 0,91 & 3,62 \\
\hline jitP “ta"(\%) & $2,10( \pm 1,02)$ & 1,72 & 1,01 & 4,83 \\
\hline jitP “ca”(\%) & $2,11( \pm 0,89)$ & 1,95 & 0,86 & 3,96 \\
\hline cvl “pa” (\%) & $2,87( \pm 1,09)$ & 2,85 & 1,34 & 6,04 \\
\hline cvl "ta" (\%) & $2,29( \pm 1,22)$ & 1,92 & 1,05 & 5,72 \\
\hline cvl "ca" (\%) & $2,89( \pm 0,97)$ & 2,86 & 1,30 & 5,26 \\
\hline
\end{tabular}


Tabela 8: Valores da DDC laríngea de crianças de nove anos do gênero masculino durante as emissões de "a" $e$ " $\mathrm{p}$ "

\begin{tabular}{|c|c|c|c|c|}
\hline Parâmetros & $\begin{array}{c}\text { Média } \\
\pm \text { desvio padrão }\end{array}$ & Mediana & $\begin{array}{l}\text { Percentil } \\
\quad 2,5\end{array}$ & $\begin{array}{l}\text { Percentil } \\
\quad 97,5\end{array}$ \\
\hline mT "a" (/s) & $3,07( \pm 0,54)$ & 3,03 & 2,16 & 4,23 \\
\hline mT "i" (/s) & $3,05( \pm 0,54)$ & 3,00 & 2,30 & 4,07 \\
\hline mP "a" (ms) & $335,13( \pm 59,20)$ & 330,06 & 236,42 & 462,75 \\
\hline mP “i” (ms) & $337,67( \pm 58,65)$ & 333,33 & 245,74 & 434,97 \\
\hline dpP “a” (ms) & $20,43( \pm 8,84)$ & 17,50 & 9,22 & 45,02 \\
\hline dpP “i” (ms) & $20,10( \pm 8,24)$ & 19,33 & 10,64 & 49,18 \\
\hline cvP "a" (\%) & $6,32( \pm 3,40)$ & 5,53 & 2,90 & 18,48 \\
\hline cvP “i” (\%) & $6,17( \pm 2,91)$ & 5,80 & 2,68 & 16,63 \\
\hline jitP “a” (\%) & $2,49( \pm 1,12)$ & 2,26 & 1,14 & 5,41 \\
\hline jitP “i” (\%) & $2,70( \pm 1,10)$ & 2,62 & 1,18 & 7,12 \\
\hline cvl "a" (\%) & $2,44( \pm 1,40)$ & 2,21 & 0,77 & 7,47 \\
\hline cvl “i” (\%) & $2,55( \pm 1,14)$ & 2,67 & 0,83 & 6,21 \\
\hline
\end{tabular}


Tabela 9: Valores da DDC oral de crianças de dez anos do gênero feminino durante as emissões "pa", "ta", "ca" e "pataca"

\begin{tabular}{|c|c|c|c|c|}
\hline Parâmetros & $\begin{array}{c}\text { Média } \\
\pm \text { desvio padrão }\end{array}$ & Mediana & $\begin{array}{l}\text { Percentil } \\
\quad 2,5\end{array}$ & $\begin{array}{l}\text { Percentil } \\
\quad 97,5\end{array}$ \\
\hline mT "pa" (/s) & $5,41( \pm 0,69)$ & 5,50 & 3,99 & 6,77 \\
\hline mT "ta" (Is) & $5,53( \pm 0,68)$ & 5,54 & 4,29 & 6,67 \\
\hline mT "ca" (/s) & $4,90( \pm 0,55)$ & 4,96 & 3,64 & 5,84 \\
\hline mT "pataca" (Is) & $1,78( \pm 0,20)$ & 1,78 & 1,31 & 2,33 \\
\hline mP "pa" (ms) & $188,11( \pm 25,69)$ & 181,82 & 147,72 & 250,43 \\
\hline mP "ta" (ms) & $183,70( \pm 23,25)$ & 180,43 & 149,92 & 233,07 \\
\hline mP “ca” (ms) & $206,77( \pm 25,71)$ & 201,72 & 171,09 & 274,80 \\
\hline dpP “pa" (ms) & $14,46( \pm 4,46)$ & 13,37 & 7,10 & 23,40 \\
\hline dpP "ta" (ms) & $16,11( \pm 10,46)$ & 13,22 & 5,83 & 56,11 \\
\hline dpP “ca" (ms) & $17,84( \pm 6,70)$ & 16,49 & 6,40 & 30,56 \\
\hline cvP “pa” (\%) & $7,68( \pm 2,03)$ & 7,25 & 3,62 & 11,06 \\
\hline cvP “ta” (\%) & $8,84( \pm 5,43)$ & 7,81 & 2,60 & 28,78 \\
\hline cvP “ca” (\%) & $8,64( \pm 3,07)$ & 8,35 & 3,32 & 14,22 \\
\hline jitP “pa”(\%) & $1,70( \pm 0,56)$ & 1,69 & 0,71 & 3,15 \\
\hline jitP “ta”(\%) & $2,08( \pm 1,81)$ & 1,78 & 0,60 & 10,09 \\
\hline jitP “ca”(\%) & $1,97( \pm 0,77)$ & 1,99 & 0,80 & 3,83 \\
\hline cvl "pa” (\%) & $2,83( \pm 1,22)$ & 2,41 & 1,40 & 5,98 \\
\hline cvl "ta" (\%) & $3,14( \pm 1,58)$ & 2,61 & 1,50 & 7,81 \\
\hline cvl "ca" (\%) & $3,04( \pm 1,38)$ & 2,40 & 0,90 & 5,80 \\
\hline
\end{tabular}


Tabela 10: Valores da DDC laríngea de crianças de dez anos do gênero feminino durante as emissões "a" $e$ " $i$ "

\begin{tabular}{|c|c|c|c|c|}
\hline Parâmetros & $\begin{array}{c}\text { Média } \\
\pm \text { desvio padrão }\end{array}$ & Mediana & $\begin{array}{l}\text { Percentil } \\
\quad 2,5\end{array}$ & $\begin{array}{l}\text { Percentil } \\
\quad 97,5\end{array}$ \\
\hline mT "a" (/s) & $3,19( \pm 0,50)$ & 3,15 & 2,37 & 4,38 \\
\hline mT “i” (/s) & $3,18( \pm 0,59)$ & 3,16 & 1,96 & 4,51 \\
\hline mP "a" (ms) & $320,57( \pm 49,98)$ & 317,13 & 228,55 & 421,54 \\
\hline mP “i” (ms) & $324,69( \pm 62,46)$ & 316,41 & 221,86 & 511,04 \\
\hline dpP "a" (ms) & $20,45( \pm 5,81)$ & 20,02 & 9,93 & 34,67 \\
\hline dpP “i” (ms) & $18,94( \pm 7,37)$ & 20,20 & 6,79 & 36,44 \\
\hline cvP "a" (\%) & $6,51( \pm 1,88)$ & 6,82 & 2,36 & 10,01 \\
\hline cvP “i” (\%) & $6,09( \pm 2,72)$ & 5,86 & 1,81 & 11,75 \\
\hline jitP “a” (\%) & $2,71( \pm 1,00)$ & 2,64 & 1,21 & 5,12 \\
\hline jitP “i” (\%) & $2,59( \pm 1,36)$ & 2,41 & 0,50 & 6,80 \\
\hline cvl “a” (\%) & $2,44( \pm 0,63)$ & 2,50 & 0,90 & 3,59 \\
\hline cvl "i” (\%) & $2,19( \pm 0,75)$ & 2,03 & 1,12 & 3,89 \\
\hline
\end{tabular}


Tabela 11: Valores da DDC oral de crianças de dez anos do gênero masculino durante as emissões "pa", "ta", "ca" e "pataca"

\begin{tabular}{|c|c|c|c|c|}
\hline Parâmetros & $\begin{array}{c}\text { Média } \\
\pm \text { desvio padrão }\end{array}$ & Mediana & $\begin{array}{l}\text { Percentil } \\
\quad 2,5\end{array}$ & $\begin{array}{l}\text { Percentil } \\
\quad 97,5\end{array}$ \\
\hline mT "pa" (Is) & $5,23( \pm 0,53)$ & 5,22 & 4,15 & 6,83 \\
\hline mT "ta" (Is) & $5,22( \pm 0,73)$ & 5,26 & 3,94 & 6,90 \\
\hline mT "ca" (Is) & $4,67( \pm 0,71)$ & 4,60 & 3,55 & 6,47 \\
\hline mT "pataca"* (Is) & $1,86( \pm 0,23)$ & 1,84 & 1,43 & 2,33 \\
\hline mP "pa" (ms) & $193,17( \pm 18,95)$ & 191,77 & 146,38 & 241,20 \\
\hline mP "ta" (ms) & $195,33( \pm 28,34)$ & 190,05 & 144,89 & 253,81 \\
\hline mP “ca" (ms) & $218,60( \pm 30,88)$ & 217,36 & 154,60 & 282,10 \\
\hline dpP “pa” (ms) & $14,93( \pm 5,08)$ & 14,22 & 7,20 & 25,79 \\
\hline dpP "ta" (ms) & $16,86( \pm 7,93)$ & 14,92 & 8,61 & 39,21 \\
\hline dpP “ca” (ms) & $23,22( \pm 12,42)$ & 19,18 & 8,76 & 56,44 \\
\hline cvP “pa” (\%) & $7,81( \pm 2,80)$ & 8,12 & 3,40 & 15,42 \\
\hline cvP “ta” (\%) & $8,75( \pm 4,22)$ & 7,11 & 3,93 & 21,78 \\
\hline cvP “ca” (\%) & $10,80( \pm 5,81)$ & 8,65 & 4,14 & 27,20 \\
\hline jitP “pa”(\%) & $1,90( \pm 0,90)$ & 1,79 & 0,70 & 4,96 \\
\hline jitP “ta”(\%) & $2,03( \pm 1,22)$ & 1,72 & 0,91 & 6,89 \\
\hline jitP “ca”(\%) & $2,69( \pm 1,71)$ & 2,06 & 0,96 & 9,29 \\
\hline cvl "pa" (\%) & $2,69( \pm 0,90)$ & 2,45 & 1,55 & 5,41 \\
\hline cvl "ta" (\%) & $2,76( \pm 1,12)$ & 2,47 & 1,18 & 6,10 \\
\hline cvl "ca" (\%) & $3,01( \pm 1,06)$ & 2,98 & 1,23 & 4,95 \\
\hline
\end{tabular}

\footnotetext{
* Resultado referente ao total de 22 crianças
} 
Tabela 12: Valores da DDC laríngea de crianças de dez anos do gênero masculino durante as emissões "a" $e$ "i"

\begin{tabular}{|c|c|c|c|c|}
\hline Parâmetros & $\begin{array}{c}\text { Média } \\
\pm \text { desvio padrão }\end{array}$ & Mediana & $\begin{array}{l}\text { Percentil } \\
\quad 2,5\end{array}$ & $\begin{array}{l}\text { Percentil } \\
\quad 97,5\end{array}$ \\
\hline $\mathrm{mTa}(/ \mathrm{s})$ & $3,11( \pm 0,51)$ & 3,14 & 1,70 & 4,08 \\
\hline mT “i” (/s) & $3,07( \pm 0,50)$ & 3,02 & 2,12 & 4,19 \\
\hline mP "a" (ms) & $332,66( \pm 71,10)$ & 318,62 & 245,16 & 587,91 \\
\hline mP “i” (ms) & $334,24( \pm 56,64)$ & 331,10 & 238,83 & 470,95 \\
\hline dpP "a" (ms) & $24,49( \pm 13,48)$ & 19,09 & 9,45 & 60,69 \\
\hline dpP “i” (ms) & $20,19( \pm 7,16)$ & 20,00 & 6,04 & 35,17 \\
\hline cvP "a" (\%) & $7,46( \pm 3,84)$ & 6,13 & 3,29 & 16,87 \\
\hline cvP “i” (\%) & $6,14( \pm 2,28)$ & 5,84 & 2,01 & 11,89 \\
\hline jitP “a” (\%) & $3,00( \pm 1,69)$ & 2,57 & 1,02 & 7,82 \\
\hline jitP “i” (\%) & $2,59( \pm 1,12)$ & 2,34 & 0,83 & 4,97 \\
\hline cvl “a” (\%) & $2,32( \pm 1,26)$ & 1,88 & 0,43 & 5,36 \\
\hline cvl "i” (\%) & $2,45( \pm 1,14)$ & 2,05 & 0,83 & 5,41 \\
\hline
\end{tabular}


Tabela 13: Valores das médias por idade e por gênero da DDC oral durante a emissão de "pa"

\begin{tabular}{cccccc}
\hline Parâmetros & $\mathbf{8}$ & $\mathbf{9}$ & $\mathbf{1 0}$ & Masc & Fem \\
\hline $\mathbf{m T}$ & 4,85 & 5,14 & 5,32 & 5,06 & 5,14 \\
$\mathbf{m P}$ & 210,09 & 197,30 & 190,64 & 199,64 & 199,04 \\
$\mathbf{d p P}$ & 15,56 & 15,73 & 14,70 & 14,74 & 15,91 \\
$\mathbf{c v P}$ & 7,44 & 7,96 & 7,75 & 7,40 & 8,02 \\
jitP & 1,87 & 1,76 & 1,80 & 1,78 & 1,83 \\
$\mathbf{c v l}$ & 2,93 & 2,89 & 2,76 & 2,82 & 2,89 \\
\hline
\end{tabular}


Tabela 14: Comparação dos resultados das tarefas da DDC oral, para a emissão monossilábica "pa”, em relação à idade e gênero

\begin{tabular}{|c|c|c|c|c|c|c|c|c|c|}
\hline \multirow[t]{2}{*}{ Parâmetros } & \multirow[t]{2}{*}{$8 F$} & \multirow[t]{2}{*}{$8 \mathrm{M}$} & \multirow[t]{2}{*}{$9 F$} & \multirow[t]{2}{*}{$9 M$} & \multirow[t]{2}{*}{$10 \mathrm{~F}$} & \multirow[t]{2}{*}{$10 \mathrm{M}$} & \multicolumn{2}{|c|}{ Anova } & \multirow[t]{2}{*}{ Tuckey } \\
\hline & & & & & & & Efeito & p & \\
\hline \multirow[t]{3}{*}{ mT } & 4,77 & 4,92 & 5,23 & 5,04 & 5,41 & 5,23 & I & 0,001 & $10>8$ \\
\hline & & & & & & & $G$ & 0,467 & \\
\hline & & & & & & & $I / G$ & 0,320 & \\
\hline \multirow[t]{3}{*}{$\mathrm{mP}$} & 214,67 & 205,51 & 194,34 & 200,25 & 188,11 & 193,17 & 1 & 0,001 & $8>9 ; 8>10$ \\
\hline & & & & & & & $G$ & 0,881 & \\
\hline & & & & & & & $I / G$ & 0,234 & \\
\hline \multirow[t]{3}{*}{ dpP } & 16,97 & 14,14 & 16,30 & 15,16 & 14,46 & 14,93 & I & 0,680 & \\
\hline & & & & & & & $G$ & 0,258 & \\
\hline & & & & & & & $I / G$ & 0,425 & \\
\hline \multirow[t]{3}{*}{ cvP } & 8,02 & 6,85 & 8,37 & 7,55 & 7,68 & 7,81 & I & 0,682 & \\
\hline & & & & & & & G & 0,211 & \\
\hline & & & & & & & $\mathrm{I} / \mathrm{G}$ & 0,532 & \\
\hline \multirow[t]{3}{*}{ jitP } & 2,05 & 1,69 & 1,75 & 1,76 & 1,70 & 1,90 & 1 & 0,764 & \\
\hline & & & & & & & $\mathrm{G}$ & 0,688 & \\
\hline & & & & & & & $I / G$ & 0,206 & \\
\hline \multirow[t]{3}{*}{ cvl } & 2,95 & 2,91 & 2,90 & 2,87 & 2,83 & 2,69 & 1 & 0,755 & \\
\hline & & & & & & & G & 0,717 & \\
\hline & & & & & & & I/G & 0,963 & \\
\hline
\end{tabular}

Legenda:

I = idade

$\mathrm{G}=$ gênero

I/G = idade/gênero 
Tabela 15: Valores das médias por idade e por gênero da DDC oral durante a emissão de "ta"

\begin{tabular}{cccccc}
\hline Parâmetros & $\mathbf{8}$ & $\mathbf{9}$ & $\mathbf{1 0}$ & Masc & Fem \\
\hline $\mathbf{m T}$ & 4,95 & 5,25 & 5,38 & 5,07 & 5,31 \\
$\mathbf{m P}$ & 206,08 & 193,05 & 189,52 & 200,45 & 191,98 \\
$\mathbf{d p P}$ & 15,59 & 17,13 & 16,49 & 17,29 & 15,50 \\
$\mathbf{c v P}$ & 7,63 & 8,83 & 8,80 & 8,64 & 8,19 \\
jitP & 1,82 & 2,02 & 2,06 & 1,98 & 1,95 \\
$\mathbf{c v l}$ & 2,68 & 2,32 & 2,95 & 2,55 & 2,74 \\
\hline
\end{tabular}


Tabela 16: Comparação dos resultados das tarefas da DDC oral, para a emissão monossilábica "ta", em relação à idade e gênero

\begin{tabular}{|c|c|c|c|c|c|c|c|c|c|}
\hline \multirow[t]{2}{*}{ Parâmetros } & \multirow[t]{2}{*}{$8 F$} & \multirow[t]{2}{*}{$8 \mathrm{M}$} & \multirow[t]{2}{*}{$9 F$} & \multirow[t]{2}{*}{$9 \mathrm{M}$} & \multirow[t]{2}{*}{$10 \mathrm{~F}$} & \multirow[t]{2}{*}{$10 \mathrm{M}$} & \multicolumn{2}{|c|}{ Anova } & \multirow[t]{2}{*}{ Tuckey } \\
\hline & & & & & & & Efeito & p & \\
\hline \multirow[t]{3}{*}{ mT } & 4,97 & 4,93 & 5,44 & 5,05 & 5,53 & 5,22 & I & 0,005 & $10>8$ \\
\hline & & & & & & & $G$ & 0,026 & $\mathrm{~F}>\mathrm{M}$ \\
\hline & & & & & & & $I / G$ & 0,372 & \\
\hline \multirow[t]{3}{*}{$\mathrm{mP}$} & 206,79 & 205,37 & 185,44 & 200,65 & 183,70 & 195,33 & I & 0,005 & $8>9 ; 8>10$ \\
\hline & & & & & & & G & 0,051 & \\
\hline & & & & & & & $I / G$ & 0,254 & \\
\hline \multirow[t]{3}{*}{ dpP } & 14,86 & 16,31 & 15,54 & 18,71 & 16,11 & 16,86 & I & 0,655 & \\
\hline & & & & & & & $G$ & 0,194 & \\
\hline & & & & & & & $I / G$ & 0,760 & \\
\hline \multirow[t]{3}{*}{ cvP } & 7,35 & 7,90 & 8,38 & 9,27 & 8,84 & 8,75 & I & 0,258 & \\
\hline & & & & & & & G & 0,503 & \\
\hline & & & & & & & $I / G$ & 0,833 & \\
\hline \multirow[t]{3}{*}{ jitP } & 1,84 & 1,80 & 1,94 & 2,10 & 2,08 & 2,03 & 1 & 0,546 & \\
\hline & & & & & & & G & 0,906 & \\
\hline & & & & & & & $I / G$ & 0,879 & \\
\hline \multirow[t]{3}{*}{ cvl } & 2,74 & 2,61 & 2,34 & 2,29 & 3,14 & 2,76 & 1 & 0,025 & $10>9$ \\
\hline & & & & & & & G & 0,334 & \\
\hline & & & & & & & I/G & 0,763 & \\
\hline
\end{tabular}

Legenda:

I = idade

$\mathrm{G}=$ gênero

I/G = idade/gênero 
Tabela 17: Valores das médias por idade e por gênero da DDC oral durante a emissão de "ca"

\begin{tabular}{crrrrr}
\hline Parâmetros & \multicolumn{1}{c}{$\mathbf{8}$} & \multicolumn{1}{c}{$\mathbf{9}$} & \multicolumn{1}{c}{10} & \multicolumn{1}{c}{ Masc } & \multicolumn{1}{c}{ Fem } \\
\hline mT & 4,37 & 4,69 & 4,79 & 4,55 & 4,68 \\
mP & 235,02 & 217,49 & 212,69 & 225,64 & 217,82 \\
dpP & 18,38 & 18,33 & 20,53 & 19,97 & 18,18 \\
cvP & 7,76 & 8,45 & 9,72 & 8,93 & 8,36 \\
jitP & 2,08 & 2,15 & 2,33 & 2,31 & 2,06 \\
cvl & 2,92 & 2,87 & 3,03 & 2,90 & 2,97 \\
\hline
\end{tabular}


Tabela 18: Comparação dos resultados das tarefas da DDC oral, para a emissão monossilábica "ca", em relação à idade e gênero

\begin{tabular}{|c|c|c|c|c|c|c|c|c|c|}
\hline \multirow[t]{2}{*}{ Parâmetros } & \multirow[t]{2}{*}{$8 F$} & \multirow[t]{2}{*}{$8 \mathrm{M}$} & \multirow[t]{2}{*}{$9 F$} & \multirow[t]{2}{*}{$9 \mathrm{M}$} & \multirow[t]{2}{*}{$10 \mathrm{~F}$} & \multirow[t]{2}{*}{$10 \mathrm{M}$} & \multicolumn{2}{|c|}{ Anova } & \multirow[t]{2}{*}{ Tuckey } \\
\hline & & & & & & & Efeito & p & \\
\hline \multirow[t]{3}{*}{ mT } & 4,39 & 4,34 & 4,74 & 4,64 & 4,90 & 4,67 & I & 0,005 & $9>8 ; 10>8$ \\
\hline & & & & & & & $G$ & 0,240 & \\
\hline & & & & & & & $I / G$ & 0,774 & \\
\hline \multirow[t]{3}{*}{$\mathrm{mP}$} & 233,15 & 236,89 & 213,55 & 221,42 & 206,77 & 218,60 & I & 0,004 & $8>9 ; 8>10$ \\
\hline & & & & & & & G & 0,165 & \\
\hline & & & & & & & $I / G$ & 0,841 & \\
\hline \multirow[t]{3}{*}{$d p P$} & 17,99 & 18,76 & 18,72 & 17,93 & 17,84 & 23,22 & I & 0,358 & \\
\hline & & & & & & & $G$ & 0,214 & \\
\hline & & & & & & & $I / G$ & 0,190 & \\
\hline \multirow[t]{3}{*}{ cvP } & 7,74 & 7,78 & 8,69 & 8,21 & 8,64 & 10,80 & I & 0,028 & $10>8$ \\
\hline & & & & & & & G & 0,339 & \\
\hline & & & & & & & $I / G$ & 0,169 & \\
\hline \multirow[t]{3}{*}{ jitP } & 2,02 & 2,13 & 2,18 & 2,11 & 1,97 & 2,69 & 1 & 0,509 & \\
\hline & & & & & & & G & 0,181 & \\
\hline & & & & & & & $I / G$ & 0,188 & \\
\hline \multirow[t]{3}{*}{ cvl } & 3,04 & 2,79 & 2,84 & 2,89 & 3,04 & 3,01 & 1 & 0,781 & \\
\hline & & & & & & & G & 0,693 & \\
\hline & & & & & & & $I / G$ & 0,793 & \\
\hline
\end{tabular}

Legenda:

I = idade

$\mathrm{G}=$ gênero

I/G = idade/gênero 
Tabela 19: Valores das médias por idade e por gênero da DDC oral durante a emissão de "pataca"

\begin{tabular}{cccccc}
\hline Parâmetros & $\mathbf{8}$ & $\mathbf{9}$ & $\mathbf{1 0}$ & Masc & Fem \\
\hline $\mathbf{m T}$ & 1,55 & 1,70 & 1,82 & 1,73 & 1,65 \\
\hline
\end{tabular}

Tabela 20: Comparação dos resultados das tarefas da DDC oral, para a emissão trissilábica "pataca", em relação à idade e gênero

\begin{tabular}{|c|c|c|c|c|c|c|c|c|c|}
\hline \multirow[t]{2}{*}{ Parâmetros } & \multirow[t]{2}{*}{$8 F$} & \multirow[t]{2}{*}{$8 \mathrm{M}$} & \multirow[t]{2}{*}{$9 F$} & \multirow[t]{2}{*}{$9 \mathrm{M}$} & \multirow[t]{2}{*}{$10 \mathrm{~F}$} & \multirow[t]{2}{*}{$10 \mathrm{M}$} & \multicolumn{2}{|c|}{ Anova } & \multirow[t]{2}{*}{ Tuckey } \\
\hline & & & & & & & Efeito & $\mathbf{p}$ & \\
\hline \multirow[t]{7}{*}{$\mathrm{mT}$} & 1,44 & 1,66 & 1,72 & 1,68 & 1,78 & 1,86 & I & 2,774 & \\
\hline & & & & & & & $G$ & 0,030 & \\
\hline & & & & & & & & & $10 \mathrm{M}>8 \mathrm{~F}$ \\
\hline & & & & & & & & & $10 \mathrm{~F}>8 \mathrm{~F}$ \\
\hline & & & & & & & I/G & 0,049 & $9 \mathrm{~F}>8 \mathrm{~F}$ \\
\hline & & & & & & & & & $9 \mathrm{M}>8 \mathrm{~F}$ \\
\hline & & & & & & & & & $8 M>8 F$ \\
\hline
\end{tabular}


Tabela 21: Valores das médias por idade e por gênero da DDC laríngea durante a emissão de "a"

\begin{tabular}{cccccc}
\hline Parâmetros & $\mathbf{8}$ & $\mathbf{9}$ & $\mathbf{1 0}$ & Masc & Fem \\
\hline mT & 2,97 & 3,15 & 3,15 & 3,07 & 3,10 \\
mP & 343,48 & 328,67 & 326,62 & 335,43 & 330,41 \\
dpP & 22,46 & 20,29 & 22,47 & 22,20 & 21,28 \\
cvP & 6,62 & 6,36 & 6,99 & 6,77 & 6,54 \\
jitP & 2,60 & 2,56 & 2,86 & 2,67 & 2,67 \\
cvl & 2,66 & 2,49 & 2,38 & 2,37 & 2,65 \\
\hline
\end{tabular}


Tabela 22: Comparação dos resultados das tarefas da DDC laríngea, para a emissão da vogal "a", em relação à idade e gênero

\begin{tabular}{|c|c|c|c|c|c|c|c|c|}
\hline \multirow[t]{2}{*}{ Parâmetros } & \multirow[t]{2}{*}{$8 F$} & \multirow[t]{2}{*}{$8 \mathrm{M}$} & \multirow[t]{2}{*}{$9 F$} & \multirow[t]{2}{*}{$9 M$} & \multirow[t]{2}{*}{$10 \mathrm{~F}$} & \multirow[t]{2}{*}{$10 \mathrm{M}$} & \multicolumn{2}{|c|}{ Anova } \\
\hline & & & & & & & Efeito & $\mathbf{P}$ \\
\hline \multirow[t]{3}{*}{ mT } & 2,90 & 3,04 & 3,22 & 3,07 & 3,19 & 3,11 & 1 & 0,143 \\
\hline & & & & & & & $\mathrm{G}$ & 0,709 \\
\hline & & & & & & & I/G & 0,352 \\
\hline \multirow[t]{3}{*}{$\mathrm{mP}$} & 348,46 & 338,50 & 322,21 & 335,13 & 320,57 & 332,66 & I & 0,281 \\
\hline & & & & & & & G & 0,594 \\
\hline & & & & & & & $I / G$ & 0,530 \\
\hline \multirow[t]{3}{*}{ dpP } & 23,24 & 21,67 & 20,15 & 20,43 & 20,45 & 24,49 & 1 & 0,413 \\
\hline & & & & & & & G & 0,552 \\
\hline & & & & & & & $I / G$ & 0,319 \\
\hline \multirow[t]{3}{*}{ cvP } & 6,72 & 6,52 & 6,40 & 6,32 & 6,51 & 7,46 & 1 & 0,570 \\
\hline & & & & & & & G & 0,642 \\
\hline & & & & & & & I/G & 0,569 \\
\hline \multirow[t]{3}{*}{ jitP } & 2,67 & 2,53 & 2,62 & 2,49 & 2,71 & 3,00 & 1 & 0,415 \\
\hline & & & & & & & G & 0,968 \\
\hline & & & & & & & $I / G$ & 0,603 \\
\hline \multirow[t]{3}{*}{ cvl } & 2,96 & 2,36 & 2,54 & 2,44 & 2,44 & 2,32 & I & 0,462 \\
\hline & & & & & & & $G$ & 0,143 \\
\hline & & & & & & & I/G & 0,451 \\
\hline
\end{tabular}

Legenda:

I = idade

$G=$ gênero

I/G = idade/gênero 
Tabela 23: Valores das médias por idade e por gênero da DDC laríngea durante a emissão de "i"

\begin{tabular}{cccccc}
\hline Parâmetros & $\mathbf{8}$ & $\mathbf{9}$ & $\mathbf{1 0}$ & Masc & Fem \\
\hline $\mathbf{m T}$ & 2,91 & 3,14 & 3,13 & 3,06 & 3,05 \\
$\mathbf{m P}$ & 352,65 & 328,83 & 329,47 & 335,41 & 338,55 \\
$\mathbf{d p P}$ & 26,89 & 21,11 & 19,57 & 21,48 & 23,56 \\
$\mathbf{c v P}$ & 7,54 & 6,73 & 6,12 & 6,51 & 7,08 \\
jitP & 3,38 & 2,80 & 2,59 & 2,78 & 3,06 \\
$\mathbf{c v l}$ & 2,66 & 2,60 & 2,32 & 2,49 & 2,56 \\
\hline
\end{tabular}


Tabela 24: Comparação dos resultados das tarefas da DDC laríngea, para a emissão da vogal “i”, em relação à idade e gênero

\begin{tabular}{|c|c|c|c|c|c|c|c|c|c|}
\hline \multirow{2}{*}{ Parâmetros } & \multirow{2}{*}{$8 F$} & \multirow{2}{*}{$8 \mathrm{M}$} & \multirow{2}{*}{$9 F$} & \multirow{2}{*}{$9 M$} & \multirow{2}{*}{$10 \mathrm{~F}$} & \multirow{2}{*}{$10 \mathrm{M}$} & \multicolumn{2}{|c|}{ Anova } & \multirow{2}{*}{ Tuckey } \\
\hline & & & & & & & Efeito & $\mathbf{P}$ & \\
\hline \multirow[t]{3}{*}{ mT } & 2,75 & 3,07 & 3,22 & 3,05 & 3,18 & 3,07 & I & 0,056 & \\
\hline & & & & & & & $G$ & 0,887 & \\
\hline & & & & & & & I/G & 0,040 & $\begin{array}{c}10 \mathrm{~F}>8 \mathrm{~F} \\
9 \mathrm{~F}>8 \mathrm{~F}\end{array}$ \\
\hline \multirow[t]{3}{*}{$\mathrm{mP}$} & 370,97 & 334,32 & 319,99 & 337,67 & 324,69 & 334,24 & I & 0,065 & \\
\hline & & & & & & & $\mathrm{G}$ & 0,739 & \\
\hline & & & & & & & $I / G$ & 0,042 & $8 \mathrm{~F}>9 \mathrm{~F}$ \\
\hline \multirow[t]{3}{*}{$d p P$} & 29,62 & 24,15 & 22,11 & 20,10 & 18,94 & 20,19 & I & 0,007 & $8>9 ; 8>10$ \\
\hline & & & & & & & $G$ & 0,290 & \\
\hline & & & & & & & I/G & 0,376 & \\
\hline \multirow[t]{3}{*}{ cvP } & 7,85 & 7,23 & 7,29 & 6,17 & 6,09 & 6,14 & 1 & 0,133 & \\
\hline & & & & & & & G & 0,330 & \\
\hline & & & & & & & I/G & 0,710 & \\
\hline \multirow[t]{3}{*}{ jitP } & 3,71 & 3,05 & 2,89 & 2,70 & 2,59 & 2,59 & 1 & 0,030 & $8>10$ \\
\hline & & & & & & & $G$ & 0,255 & \\
\hline & & & & & & & $I / G$ & 0,536 & \\
\hline \multirow[t]{3}{*}{ cvl } & 2,86 & 2,46 & 2,64 & 2,55 & 2,19 & 2,45 & 1 & 0,331 & \\
\hline & & & & & & & $G$ & 0,689 & \\
\hline & & & & & & & $I / G$ & 0,381 & \\
\hline
\end{tabular}

Legenda:

I = idade

$\mathrm{G}=$ gênero

I/G = idade/gênero 
5 - DISCUSSÃO 


\section{DISCUSSÃO}

A avaliação da DDC em crianças tem sido utilizada com o intuito de melhor compreender o processo de desenvolvimento dessa habilidade. Para que os seus resultados possam ser interpretados e assim, contribuir nos processos de avaliação e reabilitação da comunicação, o desempenho em testes de DDC oral e laríngea de crianças de oito, nove e dez anos de idade, falantes do português brasileiro foi estudado. Durante a realização desse estudo, os parâmetros da DDC foram caracterizados e correlacionados de acordo com o gênero e a idade. Para que o teste possa vir a ser utilizado na prática clínica, bem como servir como base para outros estudos, foi definido o método de realização dessa avaliação.

As emissões gravadas foram editadas, padronizando-se a exclusão dos segundos iniciais e finais, com o objetivo de eliminar possíveis instabilidades, comuns nesses momentos da emissão (PTACEK et al. ${ }^{49}$, 1966, BEHLAU et al. ${ }^{5}$, 2001). O programa utilizado para a análise da DDC foi o Motor Speech Profile Advanced (MSP), da Kay Elemetrics Corp., o qual realiza a extração automática de diversos parâmetros, dentre eles, o parâmetro denominado média da taxa da DDC, o qual refere-se ao número de vocalizações por segundo e que representa a velocidade de repetição. Para as emissões "pa", "ta”, "ca", "a” e "i” o programa realiza a extração adequada do número de emissões por segundo, desde que sejam tomados os cuidados descritos na seção de Métodos. Já a trissílaba "pataca" foi analisada apenas quanto ao número de emissões por segundo, utilizando-se o programa Mult Speech Main Program, também da Kay Elemetrics Corp. Neste caso, a contagem do número de seqüências trissilábicas por segundo foi realizada pela avaliadora, de forma manual, com o apoio da pista visual do espectrograma e da pista auditiva, depois de demarcado o tempo a ser analisado. O uso de outro programa para a análise da trissílaba deve-se a dois fatores. O primeiro refere-se à contagem das emissões; pode-se observar que o MSP não analisa esta seqüência como uma única emissão, mas sim, como três monossílabas. 0 outro fator refere-se à avaliação de ritmo da emissão, o qual não é regular entre as três sílabas devido à acentuação natural que a criança realiza durante a produção de "pataca". Isso pode ser identificado visualmente no 
espectrograma da Figura 1, onde se observa aumento de intensidade e prolongamento da última sílaba da seqüência trissilábica. Sendo assim, os parâmetros do $M S P$, que medem a duração das emissões e indicam a habilidade em manter a taxa de vocalizações constante, poderiam ser fortemente influenciados por essa característica da trissílaba. Um estudo futuro sobre a análise da DDC da seqüência trissilábica "pataca" quanto aos parâmetros fornecidos pelo MSP poderia ser realizado de forma específica, para se identificar as contribuições desse método no conhecimento do controle motor oral das crianças.

Foram definidos os valores de referência da DDC oral e laríngea para o grupo estudado, apresentados em valores de média, mediana e percentis, em função do gênero e faixa etária (Tabelas de 1 a 12). Não foram realizadas comparações quanto ao número de emissões por segundo obtidos em outros estudos, uma vez que as crianças participantes eram falantes de outras línguas. Além disso, fatores relacionados às características do desenvolvimento físico de crianças de regiões distintas podem interferir no resultado final da DDC (PRATHANEE; THANAVIRATANANICH; PONGJANYAKUL $\left.{ }^{46}, 2003\right)$. Poucos são os estudos nacionais sobre a tarefa de DDC, tanto em crianças (BRASOLOTTO; BEHLAU ${ }^{7}, 2001$ ), quanto em adultos e idosos (CARRARA-de-ANGELIS ${ }^{10}, 2000$, MOURÃO ${ }^{38}, 2002$, MEUER et al. ${ }^{37}$, 2004, PEREIRA et al. ${ }^{44}, 2004$, DEPRET $\left.{ }^{13}, 2005\right)$ e a maioria desses estudos enfocaram a avaliação em pacientes com alterações da comunicação.

No que se refere aos parâmetros fornecidos pelo programa MSP, nota-se que alguns deles apresentam análises quanto à quantidade e à duração das emissões, enquanto outros fornecem dados quanto à regularidade e estabilidade das emissões, o que proporciona uma análise qualitativa da DDC.

Vale ressaltar que, dentre os parâmetros quantitativos, a taxa da DDC representa o número de emissões produzidas por segundo, indicando a velocidade em produzir repetições rápidas, por meio de movimentos rápidos e alternados. Porém, a taxa da DDC é influenciada por outro parâmetro, denominado período, o qual é definido como o tempo médio entre as vocalizações, sendo que esta medida representa o tempo transcorrido do início de uma emissão até o ponto que antecede o início da outra emissão. Sendo 
assim, a taxa elevada da DDC é representada pelo aumento do número de emissões por segundo, em decorrência do menor tempo médio entre as vocalizações.

Serão discutidas a seguir, as comparações entre os grupos quanto aos valores quantitativos da DDC oral, sendo que, primeiramente serão apresentados os resultados em relação às monossílabas e, a seguir, em relação à trissílaba. Quanto à taxa da DDC, tanto na repetição da sílaba "pa", quanto na repetição da sílaba "ta", pode-se verificar que as crianças de dez anos produziram maior número de emissões por segundo em comparação às crianças de oito anos (Tabelas 13 a 16), porém, na repetição da sílaba "ca" além da correlação entre estas duas faixas etárias, observou-se que as crianças de nove anos produziram maior número de emissões por segundo, em comparação às de oito anos (Tabelas 17 e 18). De forma geral, as crianças mais velhas apresentaram maior taxa da DDC para as monossílabas, o que significa melhor desempenho nessa tarefa. Uma vez que a taxa da DDC é influenciada pelo tempo médio entre as vocalizações, observou-se que o período da DDC foi menor para as crianças de nove e dez, quando comparado com as de oito anos (Tabelas 13 a 18) para as repetições monossilábicas de "pa", "ta" e "ca", o que demonstra que crianças mais novas levaram um tempo maior entre o início de uma emissão até o início da próxima emissão. Desta forma, pode-se verificar que o desempenho na DDC melhorou com o aumento da idade em relação ao aspecto quantitativo.

A maior parte dos estudos que compararam os resultados da DDC oral em diferentes idades infantis, incluindo a faixa de oito a dez anos, verificou o aumento da taxa da DDC em função do aumento da idade, dentre eles os estudos de BLOMQUIST ${ }^{6}, 1950$, com crianças de nove a onze anos; o estudo de IRWIN; BECKLUND ${ }^{27}$, 1953, com crianças nas faixas etárias de seis a quinze; FLETCHER ${ }^{21}$, 1972, com crianças com idade entre seis e treze anos; DWORKIN $^{17}$, 1978, com crianças de sete a doze anos; HASELAGER; SLIS; RIETVELD ${ }^{24}$, 1991, com crianças de aproximadamente cinco a onze anos; OLIVER et al. ${ }^{42}$, 1985, em uma população de oito a dezesseis anos. No estudo de PRATHANEE; THANAVIRATANANICH; PONGJANYAKUL ${ }^{46}$, 2003, em crianças tailandesas com idades entre seis e treze anos, foi verificado 
diminuição do tempo transcorrido para a produção das seqüências, conforme a idade aumentava.

Mesmo em estudos sobre DDC em crianças que não incluíam a faixa de oito a dez anos, foi observado aumento da taxa da DDC em função do avanço da idade, como evidenciado pelos estudos de ROBBINS; KLEE ${ }^{53}$, 1987, HENRY ${ }^{25}$, 1990, com exceção de TOWNE ${ }^{58}, 1994$.

Em relação às comparações dos resultados da DDC oral das monossílabas quanto ao gênero, os parâmetros quantitativos referentes à taxa da DDC e ao período entre as vocalizações permitem observar que na repetição de "pa", e "ca", de forma geral, não houve diferença entre os gêneros, tanto para o número de emissões, quanto para o valor do tempo médio entre as emissões (Tabelas 13, 14, 17 e 18). Porém, na repetição de "ta", a taxa da DDC foi maior para as meninas em comparação aos meninos (Tabelas 15 e 16). O tempo médio entre as vocalizações foi menor para as meninas durante a repetição do "ta", porém, o valor não foi estatisticamente significante ( $p=$ 0,051), mas muito próximo do nível de significância (Tabelas 15 e 16).

Nos estudos sobre a DDC oral em crianças, observa-se forte correlação entre idades mais avançadas e melhor desempenho quanto aos valores quantitativos da DDC. Já quando se considera os gêneros, a correlação com o desempenho na DDC nem sempre é observada. Os meninos apresentaram taxas da DDC mais elevadas que as meninas nas avaliações de OLIVER et al. $^{42}$, 1985, PRATHANEE; THANAVIRATANANICH; PONGJANYAKUI ${ }^{46}$, 2003. De acordo com FLETCHER ${ }^{21}$, 1972, as meninas tenderam a ser mais rápidas na produção de monossílabos e os meninos mais rápidos na repetição de polissílabos. Em diversos estudos sobre a DDC em crianças não foram encontradas diferenças entre os gêneros (CANNING; ROSE $^{8}, 1974$, DWORKIN; CULATTA ${ }^{16}$, 1985, HENRY ${ }^{25}$, 1990, HASELAGER; SLIS; RIETVELD ${ }^{24}$, 1991, HALE et al. ${ }^{22}$, 1992). Alguns estudos com a população adulta também correlacionaram o efeito do gênero na tarefa da DDC, sendo que os homens foram mais rápidos que as mulheres nessa tarefa (LUNDEEN $^{34}$, 1950, DWORKIN; ARONSON $\left.{ }^{15}, 1986\right)$.

Ao contrário dos resultados da taxa da DDC para as emissões monossilábicas, nas repetições de "pataca", o fator idade não foi correlacionado à taxa da DDC (Tabelas 19 e 20), porém, vários estudos 
apontam aumento do número de emissões por segundo ou diminuição do tempo para emitir certo número de emissões, em função do aumento da idade (BLOMQUIST ${ }^{6}, \quad$ 1950, $\quad$ FLETCHER $^{21}, \quad$ 1972, PRATHANEE; THANAVIRATANANICH; PONGJANYAKUL ${ }^{46}$, 2003). Da mesma forma que no presente estudo, YARUUS; LOGAN ${ }^{67}$, 2002, não encontraram correlação entre a idade e a taxa de DDC para as emissões precisas e fluentes, durante as repetições de "puh-tuh-kuh". No entanto, no presente estudo, a taxa da DDC na emissão trissilábica "pataca" foi estatisticamente diferente entre os gêneros e a interação idade e gênero evidenciou que as crianças de dez e nove anos, de ambos os gêneros, e as crianças de oito anos do gênero masculino apresentaram maior taxa de DDC, em comparação às crianças de oito anos do gênero feminino (Tabela 20). Já no estudo de BLOMQUIST ${ }^{6}, 1950$, os meninos obtiveram escores um pouco mais altos quando comparado às meninas, exceto para a seqüência [pӘtӘkӘ].

Quanto às emissões monossilábicas e às vogais, no presente estudo, todas as crianças realizaram as repetições de forma correta. Porém, durante a tarefa da DDC das emissões trissilábicas, foi verificado que nem todas as crianças realizaram a tarefa corretamente, mesmo após várias tentativas. No trabalho de $\mathrm{TOWNE}^{58}, 1994$, as crianças sem alteração de comunicação, também realizaram as emissões monossilábicas de $/ \mathrm{t} / \mathrm{e} / \mathrm{k} / \mathrm{de}$ forma correta, sendo que no estudo de THOONEN et al. ${ }^{56}, 1996$, das onze crianças sem distúrbio motor da fala, somente seis não requisitaram tentativas adicionais para produzir corretamente a seqüência trissilábica e cinco crianças realizaram a seqüência corretamente após uma ou mais tentativas adicionais; no entanto, as onze crianças realizaram a seqüência corretamente.

Serão discutidos, a seguir, os resultados quantitativos da DDC laríngea quanto à taxa da DDC e ao período entre as vocalizações, em relação às idades. Verificou-se que só houve diferença entre as idades especificamente para as meninas, durante a repetição da vogal "i”. Para essa emissão, houve um aumento da taxa da DDC, quando se comparou as meninas de 10 e nove anos às meninas de oito anos (Tabela 24), sugerindo que, com o aumento da idade, as crianças desse gênero adquirem melhor controle motor laríngeo. Em relação ao tempo médio entre as vocalizações, as meninas de oito anos apresentaram períodos de emissões de "i" mais longos quando comparadas 
com as de nove anos (Tabela 24). Observou-se que os resultados quantitativos da DDC laríngea quanto ao "i" seguiram a mesma tendência que os resultados da DDC oral. Porém, esse comportamento não foi observado na DDC da vogal "a”, para a qual não foram encontradas diferenças entre idades e gêneros. Não há outros estudos que tenham investigado a DDC laríngea em relação à idade, em crianças, o que reforça a necessidade de outras investigações sobre o tema.

Em relação à DDC laríngea não foram encontrados muitos estudos com a população infantil, porém, nos estudos com adultos, foi demonstrado que é um teste importante na compreensão da função laríngea, em pacientes que se submeteram a hemilaringectomia e em pacientes diagnosticados com esclerose lateral amiotrófica e doença de Parkinson (KREUL ${ }^{29}$, 1972, LEEPER; HEENEMAN; REYNOLDS ${ }^{30}$, 1990, RENOUT et al. ${ }^{51}$, 1995, LEEPER et al. ${ }^{32}$, 1996), bem como, durante o processo de envelhecimento (PTACEK et al. ${ }^{49}$, 1966, SHANKS $\left.{ }^{55}, 1970\right)$, podendo ser utilizado como uma ferramenta clínica na avaliação laríngea (LEEPER; JONES ${ }^{31}$, 1991).

Além dos parâmetros discutidos até o momento, quatro outros parâmetros são fornecidos pelo programa MSP: o desvio padrão do período da DDC; o coeficiente de variação do período e o jitter do período, os quais indicam a habilidade em manter a taxa de vocalizações constante, porém, 0 primeiro mede o grau de variação da taxa no período, e o segundo mede o grau de variação ciclo-a-ciclo no período; o quarto parâmetro refere-se ao grau de variação do pico da intensidade das emissões, medindo a habilidade em manter a intensidade das vocalizações constante. Sendo assim, a oscilação ou a estabilidade das repetições podem ser analisadas por meio destes quatro parâmetros, refletindo em uma análise qualitativa, uma vez que, mesmo sendo um resultado numérico, o ritmo e/ou estabilidade estarão sendo analisados.

Serão discutidos, a seguir, os resultados da avaliação qualitativa em relação à DDC oral. Na repetição da sílaba "pa", não houve correlação entre gênero e idade, para os quatro parâmetros qualitativos. Porém, na repetição da sílaba "ta", o fator idade foi correlacionado ao parâmetro de variação da intensidade da DDC, observando-se que as crianças de dez anos foram mais instáveis que as crianças de nove anos (Tabelas 15 e 16). Já para a repetição da sílaba "ca" dentre estes quatro parâmetros, a única diferença 
estatisticamente significante foi em relação ao coeficiente de variação do período da DDC, sendo que as crianças de dez anos variaram mais que as crianças de oito anos (Tabelas 17 e 18).

Em relação à avaliação qualitativa da DDC laríngea, na repetição da vogal "i”, para estes quatro parâmetros, foi observado que o desvio padrão do período apresentou diferença estatisticamente significante em função da idade, sendo que as crianças de oito anos foram mais instáveis que as de nove e as de dez anos, em decorrência do alto valor do desvio-padrão do período (Tabelas 23 e 24), e as crianças de oito anos também apresentaram valor de jitter do período mais elevado que as de 10 (Tabelas 23 e 24). Para a DDC oral, a instabilidade das emissões analisadas por esses parâmetros foi maior para as crianças mais velhas, porém, na DDC laríngea a instabilidade foi maior para as crianças mais novas. O esperado seria que na DDC oral, as crianças mais velhas fossem também mais estáveis, acompanhando sua maior habilidade em realizar emissões mais rápidas. CANNING; ROSE ${ }^{8}$, 1974, comentaram em seu estudo que as crianças que demonstraram rápido desempenho, normalmente tiveram um ritmo melhor. Desta forma, faz-se necessário que outros estudos abordem o comportamento da DDC infantil, a fim de compreender melhor este aspecto.

BLOMQUIST $^{6}$, 1950, WHITEHILL; TSANG ${ }^{60}$, 2002, mencionaram a necessidade de investigações do ritmo ou regularidade nas tarefas da DDC. Em relação à avaliação do ritmo durante a tarefa de DDC, pela análise qualitativa, CANNING; $\mathrm{ROSE}^{8}$, 1974, referem que as crianças mais jovens tenderam à falta de ritmo e tiveram controle respiratório inferior, sendo que isto levou à velocidade reduzida. HENRY ${ }^{25}$, 1990, notou que as crianças que executavam com mais facilidade as tarefas da DDC organizaram suas repetições ritmicamente. Este autor refere também que pode haver uma relação entre memória auditiva, DDC e ritmo, uma vez que há necessidade em controlar a seqüência e o tempo, tanto no planejamento quanto na produção. No estudo de BRASOLOTTO; BEHLAU ${ }^{7}, 2001$, as crianças que apresentaram trocas entre sons surdos e sonoros, realizaram mais repetições de forma arrítmica do que as crianças que não apresentaram trocas, sendo que no trabalho de THOONEN et al. ${ }^{56}, 1996$, os valores qualitativos da DDC diferiram entre os grupos com distúrbio da comunicação. 
É relevante salientar que a análise da DDC em adultos, tanto no que se refere à taxa de produção silábica, quanto à regularidade do ritmo e controle do loudness, bem como a duração silábica, podem demonstrar diferenças, tanto em relação à idade, entre grupos com e sem distúrbio da comunicação e entre grupos com distúrbio da comunicação distintos (CANTER ${ }^{9}, 1965$, DWORKIN; ARONSON; MULDER ${ }^{14}, 1980$, PORTNOY; ARONSON ${ }^{45}, 1982$, PTACEK et al. ${ }^{49}$, 1966, PARNELL; AMERMAN ${ }^{43}$, 1987, ACKERMANN; HERTRICH; HEHR ${ }^{2}$, 1995, ZIEGLER ${ }^{69}, 2002$, MOURÃO ${ }^{38}, 2002$, LUNDY et al. ${ }^{35}, 2004$, PEREIRA et al. ${ }^{44}, 2004$, DEPRET ${ }^{13}, 2005$, ROSEN; KENT; DUFFY $^{54}, 2005$ ) e compreender a própria doença (ACKERMANN et al. ${ }^{1}, 1993$ ), bem como, entender a progressão da doença (RENOUT et al. ${ }^{51}$, 1995, NISHIO; $\mathrm{NIIMI}^{41}$, 2000). A análise da duração silábica na população infantil também demonstrou que crianças disártricas apresentaram maior e mais variada duração silábica (WIT et al. ${ }^{65}, 1993$, WIT et al. ${ }^{64}, 1994$ ).

Além dos parâmetros referentes à taxa, tempo médio entre as vocalizações, ritmo e habilidade em manter constante a intensidade, outros fatores podem ser avaliados na tarefa da DDC, tais como, a precisão dos movimentos e a consistência das respostas (WILLIAMS; STACKHOUSE ${ }^{61}$, 1998; WILLIAMS; STACKHOUSE ${ }^{62}$, 2000). No estudo de WILLIAMS; STACKHOUSE ${ }^{61}, 1998$, as crianças entre três a cinco anos apresentaram uma progressão desenvolvimental no desempenho em relação à precisão e à consistência, mas não em relação à taxa da DCC, os autores sugeriram que as medidas da consistência são mais confiáveis e mais sensíveis ao desenvolvimento, pelo menos entre três e quatro anos de idade, em comparação às medidas de precisão e taxa, embora confirmem que as tarefas de DDC utilizadas são sensíveis ao desenvolvimento e podem ser úteis em identificar crianças que não estão se desenvolvendo normalmente. WILLIAMS; STACKHOUSE $^{62}, 2000$, referem que os dados normativos referente à taxa, precisão e consistência da DDC podem contribuir para diagnósticos precisos e, com isso, auxiliar em programas de intervenção apropriados para crianças com dificuldades de fala. Outro fator que pode contribuir para o diagnóstico diferencial de distúrbios da comunicação é a avaliação do tempo máximo de fonação associados aos testes da DDC (THOONEN et al. ${ }^{56}, 1996$, THOONEN et al. $\left.{ }^{57}, 1999\right)$. 
Não foi proposta, no presente estudo, a realização de avaliações detalhadas referentes a aspectos, tais como, a avaliação miofuncional orofacial, avaliação auditiva, processamento auditivo, dentre outros, entretanto, ao se excluir crianças com manifestações de alterações na comunicação oral, por meio dos questionários, da prova de nomeação da parte $A$ do Teste ABFW WERTZNER ${ }^{59}, 2004$, e da avaliação perceptiva auditiva da voz, foi possível constituir um grupo representativo das crianças sem alterações relevantes que pudessem comprometer os resultados da DDC. Entretanto, fatores orgânicos e funcionais que não expressam necessariamente um distúrbio na comunicação oral, podem interferir nos resultados dos testes da DDC, como fatores miofuncionais orofaciais (FLETCHER; MELDRUM ${ }^{20}$, 1968, HALE et al. ${ }^{22}$, 1992, DWORKIN $^{17}, 1978$, DWORKIN $\left.{ }^{18}, 1980\right)$. FAWCETT; NICOLSON ${ }^{19}, \quad 2002$, referem lentidão durante a tarefa de DDC oral nas crianças com dislexia, decorrentes tanto do acesso fonológico e planejamento motor, quanto da velocidade mais lenta da produção do gesto articulatório. De acordo com WOLK; EDWARDS; CONTURE ${ }^{66}$, 1993, há ainda a necessidade de compreender a relação entre a DDC e a habilidade fonológica, DDC e taxas articulatórias da fala, além da DDC e a fluência da fala.

Ressalta-se que no estudo de LEWIS $^{33}$, 2004, a taxa da DDC em crianças foi utilizada no acompanhamento diagnóstico. Também tem sido utilizada em crianças com alteração articulatória, sendo que a taxa da DDC apresentada por estas crianças foi mais baixa quando comparada às taxas das crianças sem alteração articulatória $\left(\mathrm{PRINS}^{48}\right.$, 1962, YOSS; DARLEY ${ }^{68}, 1974$, WILLIAMS; INGHAM; ROSENTAL ${ }^{63}$, 1981), e as alterações encontradas durante a realização da tarefa da DDC, podem contribuir para a compreensão do processo de maturação sensorial e motora (MASON et al. ${ }^{36}, 1977$ ).

Vale comentar ainda que, embora o teste da DDC seja um teste objetivo, pode existir interferência de diversos fatores subjetivos durante a sua realização, dentre eles, a motivação da criança na realização da tarefa, uma vez que as instruções dadas às crianças podem influenciar seu desempenho (COHEN; WATERS; HEWLETT'12, 1998); a ordem fornecida "diga o som tão rapidamente quanto possível", é a ordem básica na aplicação da tarefa de DDC, porém, durante o ensinamento da prova pelo avaliador e o treino 
realizado pela criança, pode fazer com que haja a interferência da maior precisão articulatória sobre a velocidade, alterando assim o resultado da DDC.

Como em outros testes, é primordial que se tenha cuidado na aplicação da prova e na coleta dos resultados, além de cuidado e atenção durante a sua interpretação.

Finalizando, as diferenças entre idade e gênero encontradas na DDC oral e laríngea neste grupo de crianças, demonstram que o desenvolvimento da DDC dever ser considerado na avaliação da comunicação oral de crianças. 
6 - CONCLUSÕES 


\section{CONCLUSÕES}

Em relação à avaliação da DDC oral e laríngea de 150 crianças de oito a dez anos de idade, de duas escolas públicas do Ensino Fundamental da cidade de Bauru, foi possível estabelecer parâmetros de normalidade quanto aos resultados destas avaliações, caracterizando assim, estes grupos de crianças.

No que se refere à idade:

- Para as monossílabas "pa", "ta" e "ca", as crianças mais velhas produziram maior número de emissões e produziram emissões mais longas comparado às crianças mais novas;

- Para a trissílaba "pataca", as crianças de nove e dez anos, de ambos os gêneros, e os meninos de oito anos realizaram maior número de emissões quando comparados às meninas de 8 anos;

- Para a vogal "i" as meninas mais velhas produziram maior número de emissões e produziram emissões mais longas, comparado às crianças mais novas;

- Para a sílaba "ta", as crianças de dez anos apresentaram maior valor de coeficiente de variação do pico da intensidade da DDC que as de nove anos;

- Para a sílaba "ca", as crianças de dez anos apresentaram maior valor de coeficiente de variação do período da DDC que as crianças de oito anos;

- Para a vogal "i", as crianças de oito anos apresentaram maior valor de desvio-padrão do período da DDC que as crianças de nove e dez anos; as crianças de oito anos apresentaram maior valor de perturbações do período da DDC que as de dez anos.

No que se refere ao gênero:

- Para a monossílaba "ta", as meninas produziram maior número de emissões por segundo em comparação aos meninos;

- Para a trissílaba "pataca" houve diferença entre os gêneros. 
ANEXOS 


\section{ANEXOS}

\section{ANEXO 1: Termo de Aquiescência}

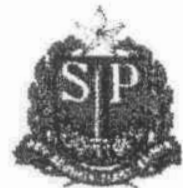

SECRETARIA DE ESTADO DA EDUCAÇÃO COORDENADORIA DE ENSINO DO INTERIOR DIRETORIA DE ENSINO - REGIÃO BAURU EE "JOÃO MARINGONI"

Rua Prof". Julieta Guedes de Mendonça, n. ${ }^{a}$ 1-50

N. Beija Flor - Bauru - S.P. CEP. 17.025-500 fone (014)3239-1381

Bauru, 01 de novembro de 2005

TERMO DE AQUIESCÊNCIA

Como parte da documentação solicitada pelo CEP _FOB-USP para a avaliação de projetos de pesquisas envolvendo seres humanos, declaramos estar ciente da realização da pesquisa "Diadococinesia Oral e Laríngea em Crianças” a ser realizada pela aluna Daniela Jovel Modolo sob orientaçăo da Profa. Dra. Alcione Ghedini Brasolotto nas dependências da Escola EE João Maringoni.

Informamos que o trabalho só poderá ser iniciado em nossas instalações, após aprovação de um Comitê de Ética em Pesquisa em Seres Humanos.

Atenciosamente,

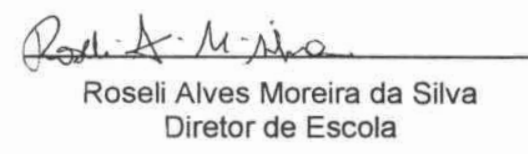

$\| \mathrm{m}^{\circ} \mathrm{Sr}$. Prof. Dr. JOSÉ HENRIQUE RUBO

DD. Coordenador do Comitê de Ética em Pesquisa - FOB/USP 


\section{ANEXO 2: Termo de Aquiescência}

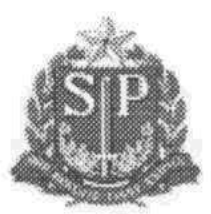

SECRETARIA DE ESTADO DA EDUCAÇ̃̃O

COORDENADORIA DE ENSINO DO INTERIOR

DIRETORIA DE ENSINO - REGIÃO DE BAURU

EE "PROF. SILVÉRIO SÃO JOÃO"

RUA: ANTONIO XAVIER DE MENDONÇA N ${ }^{\circ} .5-35$

VILA UNIVERSITÁRIA

FONE: 3223-2699

E-MAIL : ee.silvério@ig.com.br

DD. Coordenador do Comitê de Ética em Pesquisa - FOB/USP

Bauru, 26 de Outubro de 2005

TERMO DE AQUIESCÊNCIA

Como parte da documentação solicitada pelo CEP _FOB-USP para a avaliação de projetos de pesquisas envolvendo seres humanos, declaramos estar ciente da realização da pesquisa "Diadococinesia Oral e Laríngea em Crianças" a ser realizada pela aluna Daniela Jovel Modolo sob orientação da Profa. Dra. Alcione Ghedini Brasolotto nas dependências da Escola EE Professor Silvério São João.

Informamos que o trabalho só poderá ser iniciado em nossas instalações, após aprovação de um Comitê de Ética em Pesquisa em Seres Humanos.

Atenciosamente,

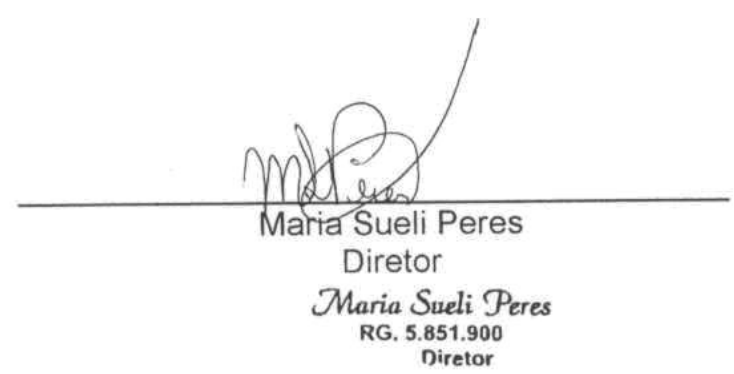

$\| m^{\circ}$ Sr. Prof. Dr. JOSÉ HENRIQUE RUBO

DD. Coordenador do Comitê de Ética em Pesquisa - FOB/USP 


\section{ANEXO 3: Carta de informação ao sujeito da pesquisa}

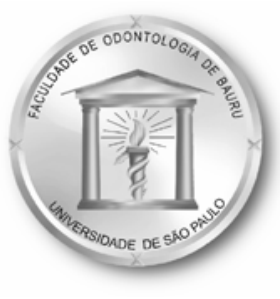

\section{Universidade de São Paulo \\ Faculdade de Odontologia de Bauru}

Al. Dr. Octávio Pinheiro Brisolla, 9-75 - Bauru-SP - CEP 17012-901 -

C.P. 73

PABX (0XX14)235-8000 - FAX (0XX14)223-4679

\section{CARTA DE INFORMAÇÃO AO SUJEITO DA PESQUISA}

Bauru, 17 de outubro de 2005

Título do Projeto: “Diadococinesia Oral e Laríngea em crianças”.

Pesquisador responsável: Fga. Daniela Jovel Modolo

Orientadora:Prof ${ }^{\mathrm{a}} \mathrm{Dr}^{\mathrm{a}}$ Alcione Ghedini Brasolotto.

Será desenvolvida uma pesquisa com o objetivo de conhecer a velocidade de repetição das vogais "a”, "i”, /u:i/, da fricativa /f:v/ e das sílabas "pa”, "ta”, "ka” e "pataka”, auxiliando assim no diagnóstico e processo terapêutico dos distúrbios da comunicação. A habilidade em realizar uma série de movimentos rápidos e sucessivos é chamada Diadococinesia.

O responsável pela criança inicialmente deverá responder um questionário sobre a saúde geral e hábitos vocais da criança. Posteriormente serão gravadas emissões rápidas das vogais "a”, “i”, “u:i” das fricativas "f:v" e das sílabas “pa”, 'ta”, "ka” e "pataka” durante 6 segundos, além de emissões durante o maior tempo possível após inspiração profunda, dos sons "a”, "i”, "u” "s", "z" e contagem dos números. As crianças também serão solicitadas repetir algumas palavras sob modelo da pesquisadora e nomear algumas figuras. Estima-se que esses procedimentos demorem aproximadamente 40 minutos.

Os procedimentos utilizados não proporcionarão riscos aos indivíduos. Os participantes estarão contribuindo para o conhecimento do comportamento de fala e voz dos seres humanos, auxiliando na elaboração de tratamentos mais efetivos para pessoas com alterações nesses comportamentos.

Os sujeitos participantes da pesquisa estarão isentos de qualquer custo, sendo que a criança não será identificado(a). Os participantes, familiares e/ou responsáveis possuem total liberdade para interromperem a avaliação assim que acharem necessário, sem contudo haver quebra no compromisso da fonoaudióloga para com vocês.

Caso haja dúvidas sobre esse projeto, o responsável pela criança poderá entrar em contato com a Fga. Daniela Jovel Modolo, pelo telefone 32143055.

Em caso de alguma reclamação em relação a sua participação nessa pesquisa, o sujeito poderá entrar em contato com o Comitê de Ética em Pesquisa da FOB-USP pelo telefone 32358356. 


\title{
ANEXO 3: Termo de consentimento livre e esclarecido
}

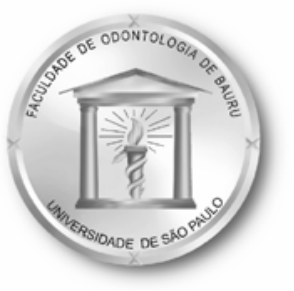

\author{
Universidade de São Paulo \\ Faculdade de Odontologia de Bauru \\ Al. Dr. Octávio Pinheiro Brisolla, 9-75 - Bauru-SP - CEP 17012-901 - \\ C.P. 73 \\ PABX (0XX14)3235-8000 - FAX (0XX14)3223-4679
}

\section{TERMO DE CONSENTIMENTO LIVRE E ESCLARECIDO}

Pelo presente instrumento que atende às exigências legais, o Sr. (a)

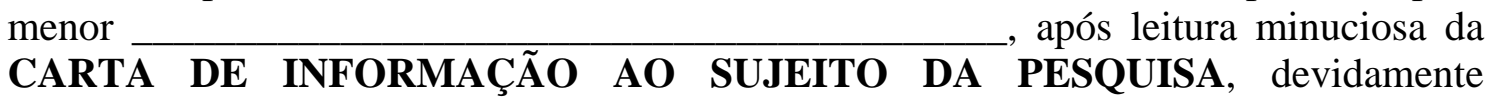
, portador da cédula de identidade responsável pelo explicada pelos profissionais em seus mínimos detalhes, ciente dos serviços e procedimentos aos quais será submetido, não restando quaisquer dúvidas a respeito do lido e explicado, firma seu CONSENTIMENTO LIVRE E ESCLARECIDO concordando em participar da pesquisa "Diadococinesia Oral em Crianças".

Fica claro que o sujeito da pesquisa ou seu representante legal pode a qualquer momento retirar seu CONSENTIMENTO LIVRE E ESCLARECIDO e deixar de participar desta pesquisa e ciente de que todas as informações prestadas tornaram-se confidenciais e guardadas por força de sigilo profissional (Art. $29^{\circ}$ do Código de Ética do Fonoaudiólogo).

Por estarem de acordo assinam o presente termo.

Bauru-SP, de de 2005.

\section{Assinatura do Responsável}

Fga. Daniela Jovel Modolo

Mestranda
Profa. Dra. Alcione Ghedini

Brasolotto

Orientadora 


\section{ANEXO 4: Questionário sobre saúde e hábitos para caracterização da população}

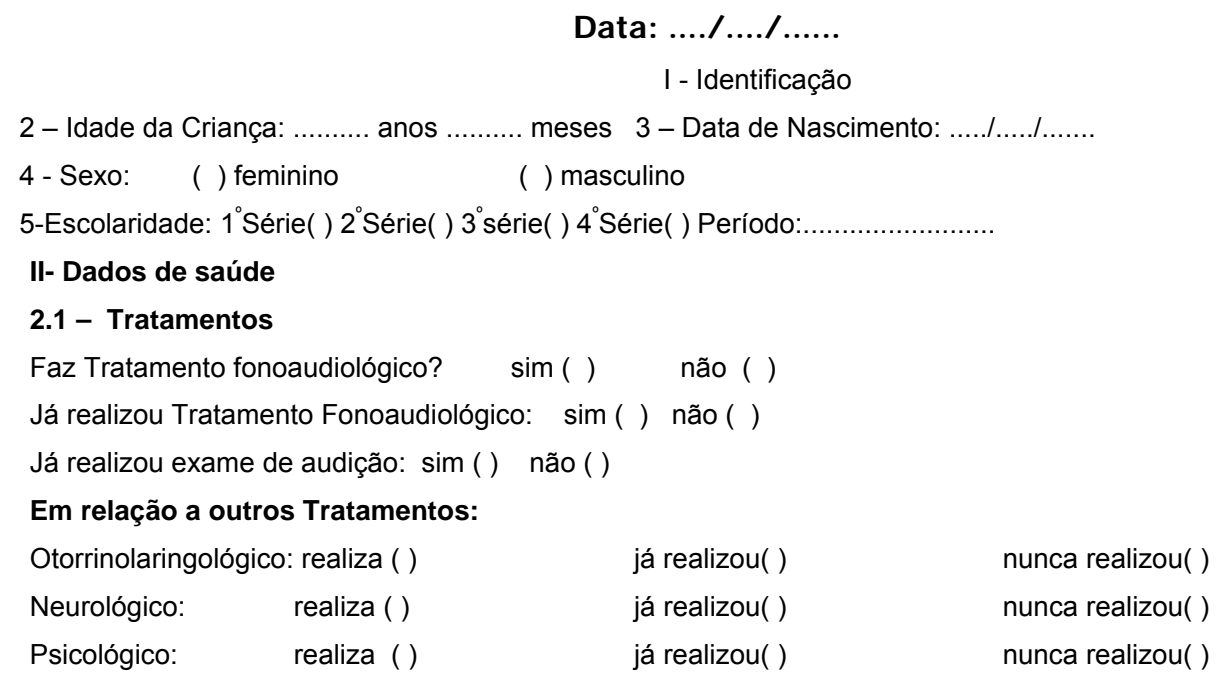

\section{2 - Doenças}

Inflamação de garganta: Apresenta ( ) Já apresentou ( ) Nunca apresentou ( ) Não soube informar ( )

Pigarro freqüente: Apresenta ( ) Já apresentou ( ) Nunca apresentou ( ) Não soube informar ( )

Aftas constantes: Apresenta ( ) Já apresentou ( ) Nunca apresentou ( ) Não soube informar ( )

Rinite: Apresenta ( ) Já apresentou ( ) Nunca apresentou ( ) Não soube informar ( )

Sinusite: Apresenta ( ) Já apresentou ( ) Nunca apresentou ( ) Não soube informar ( )

Asma: Apresenta ( ) Já apresentou ( ) Nunca apresentou ( ) Não soube informar ( )

Bronquite: Apresenta ( ) Já apresentou ( ) Nunca apresentou ( ) Não soube informar ( )

Outras doenças respiratórias: Quais?

Gripes constantes: $\quad$ Apresenta ( ) Já apresentou ( ) Nunca apresentou ( ) Não soube informar ( )

Problemas de crescimento: Apresenta ( ) Já apresentou ( ) Nunca apresentou ( ) Não soube Informar ( )

Problema Neurológico Apresenta () Já apresentou () Nunca apresentou () Não soube informar ()

Problema cardíaco: Apresenta () Já apresentou () Nunca apresentou () Não soube informar ()

Problemas Psicológicos/ psiquiátricos:

Apresenta ( ) Já apresentou ( ) Nunca apresentou ( ) Não soube informar ( )

Para as meninas: Já ocorreu a primeira menstruação? Sim（） Não（）

Utiliza algum tipo de medicamento? Qual?.

\section{3 - Uso de voz}

Fala alto (forte) demais constantemente:

$\begin{array}{ll}\operatorname{Sim}(\text { ) } & \text { Não ( ) } \\ \operatorname{Sim}(\text { ) } & \text { Não ( ) } \\ \operatorname{Sim~(~)~} & \text { Não ( ) }\end{array}$

Fala baixo (fraco) demais constantemente:

Fica rouco com freqüência: 


\begin{tabular}{|c|c|c|c|c|c|}
\hline Questão & $\mathbf{N}$ & $\%$ & Questão & $\mathbf{N}$ & $\%$ \\
\hline Tratamento Fonoaudiológico atual & 1 & $0,7 \%$ & Asma atual & 0 & $0 \%$ \\
\hline Tratamento Fonoaudiológico pregresso & 7 & $4,7 \%$ & Asma pregressa & 0 & $0 \%$ \\
\hline Exame Audiológico pregresso & 41 & $27,3 \%$ & Asma não soube informar & 2 & $1,3 \%$ \\
\hline Tratamento ORL atual & 2 & $1,3 \%$ & Bronquite atual & 0 & $0 \%$ \\
\hline Tratamento ORL pregresso & 25 & $16,7 \%$ & Bronquite pregressa & 0 & $0 \%$ \\
\hline Tratamento Neurológico atual & 0 & $0 \%$ & Bronquite não soube informar & 2 & $1,3 \%$ \\
\hline Tratamento Neurológico pregresso & 0 & $0 \%$ & Gripes constantes atual & 9 & $6,0 \%$ \\
\hline Tratamento Psicológico atual & 3 & $2 \%$ & Gripes constantes pregressa & 90 & $60 \%$ \\
\hline Tratamento Psicológico pregresso & 25 & $16,7 \%$ & Gripes não soube informar & 2 & $1,3 \%$ \\
\hline Inflamação de Garganta atual & 7 & $4,7 \%$ & Problemas de crescimento atual & 4 & $2,7 \%$ \\
\hline Inflamação de Garganta pregressa & 121 & $80,7 \%$ & Problemas de crescimento pregressos & 2 & $1,3 \%$ \\
\hline Inflamação de Garganta não soube informar & 2 & $1,3 \%$ & Problemas de crescimento não soube informar & 7 & $4,7 \%$ \\
\hline Pigarro freqüente atual & 8 & $5,3 \%$ & Problema neurológico atual & 0 & $0 \%$ \\
\hline Pigarro freqüente pregresso & 24 & $16,0 \%$ & Problema neurológico pregresso & 0 & $0 \%$ \\
\hline Pigarro freqüente não soube informar & 8 & $5,3 \%$ & Problema neurológico não soube informar & 7 & $4,7 \%$ \\
\hline Aftas constantes atual & 17 & $11,3 \%$ & Problema cardíaco atual & 0 & $0 \%$ \\
\hline Aftas constantes pregressa & 51 & $34,0 \%$ & Problema cardíaco pregresso & 3 & $2,0 \%$ \\
\hline Aftas constantes não soube informar & 7 & $4,7 \%$ & Problema cardíaco não soube informar & 3 & $2,0 \%$ \\
\hline Rinite atual & 22 & $14,7 \%$ & Problemas psicológicos/psiquiátricos atual & 3 & $2,0 \%$ \\
\hline Rinite pregressa & 29 & $19,3 \%$ & Problemas psicológicos/psiquiátricos pregresso & 9 & $6,0 \%$ \\
\hline Rinite não soube informar & 7 & $4,7 \%$ & Problemas psicológicos/psiquiátricos não soube informar & 7 & $4,7 \%$ \\
\hline Sinusite atual & 12 & $8,0 \%$ & Fala alto & 86 & $57,3 \%$ \\
\hline Sinusite pregressa & 31 & $20,7 \%$ & Fala baixo & 10 & $6,7 \%$ \\
\hline \multirow[t]{2}{*}{ Sinusite não soube informar } & 5 & $3,3 \%$ & Fica rouco com freqüência & 11 & $7,3 \%$ \\
\hline & & & Menstruação & 0 & $0 \%$ \\
\hline
\end{tabular}


REFERÊNCIAS 


\section{REFERÊNCIAS}

1 Ackermann H, Grone BF, Hoch G, Schonle PW. Speech freezing in Parkinson's disease: a kinematic analysis of orofacial movements by means of electromagnetic articulography. Folia Phoniatr (Basel). 1993;45(2):84-9.

2 Ackermann $\mathrm{H}$, Hertrich I, Hehr T. Oral diadochokinesis in neurological dysarthrias. Folia Phoniatr Logop. 1995;47(1):15-23

3 Andrade CRF de, Befi-Lopes DM, Fernandes FDM, Wetzner HF. ABFW: teste de linguagem Infantil nas áreas de fonologia, vocabulário, fluência e pragmática. 2. ed. Carapicuíba: Pró-Fono; 2004.

4 Baken RJ, Orlikoff RF. Speech movements. In: Baken RJ, Orlikoff RF. Clinical measurement speech and voice. 2nd ed. San Diego: Singular Thomson Learning; 2000. p. 511-57.

5 Behlau M, Madazio G, Feijó D, Pontes P. In: Behlau M, organizadora. Voz: o livro do especialista. Rio de janeiro: Revinter; 2001. v.1, p. 85-245.

6 Blomquist BL. Diadochokinetic movements of nine-, ten,- and eleven yearold children. J Speech Disord. 1950;15(2):159-64.

7 Brasolotto AG, Behlau M. Análise acústica da voz e diadococinesia oral em crianças que substituem sons sonoros por surdos. In: Behlau M. A voz do especialista. Rio de janeiro: Revinter; 2001. v. 2, p. 49-63.

8 Canning BA, Rose MF. Clinical measurements of the speed of tongue and lip movements in British children with normal speech. Br J Disord Commun. 1974;9(1):45-50. 
9 Canter GJ. Speech characteristics of patients with Parkinson's disease: III. articulation, diadochokinesis; and over all speech adequacy. J Speech Hear Disord. 1965;30(3):217-24.

10 Carrara-de Angelis E. Deglutição, configuração laríngea, análise clínica e acústica computadorizada da voz de pacientes com doença de Parkinson [tese]. São Paulo (SP): Escola Paulista de Medicina, Universidade Federal de São Paulo; 2000.

11 Chuma AV, Cacace AT, Rosen R, Feustel P, Koltaii PJ. Effects of tonsillectomy and/or adenoidectomy on vocal function: laryngeal, supralaryngeal and perceptual characteristics. Int J Pediatr Otorhinolaryngol. 1999;47(1):1-9.

12 Cohen W, Waters D, Hewlett N. DDK rates in the paediatric clinic: a methodological minefield. Int J Lang Commun Disord. 1998;33 Suppl:42833.

13 Depret MMP. Análise da diadococinesia articulatória e laríngea em indivíduos com e sem transtornos neurológicos. [tese]. São Paulo (SP): Escola Paulista de Medicina, Universidade Federal de São Paulo; 2005.

14 Dworkin JP, Aronson AE, Mulder DW. Tongue force in normals and in dysarthric patients with amyotrophic lateral sclerosis. J Speech Hear Res. 1980;23(4):828-37.

15 Dworkin JP, Aronson AE. Tongue strength and alternate motion rates in normal and dysarthric subjects. J Commun Disord. 1986;19:115-132

16 Dworkin JP, Culatta RA. Oral structural and neuromuscular characteristics in children with normal and disordered articulation. J Speech Hear Disord. 1985;50(2):150-6. 
17 Dworking JP. Protusive lingual force and lingual diadochokinetic rates: a comparative analysis between normal and lisping speakers. Lang Speech Hear Serv Sch. 1978;19:8-16.

18 Dworking JP. Characteristics of frontal lispers clustered according to severity. J Speech Hear Disord. 1980;45(1):37-44.

19 Fawcett AJ, Nicolson RI. Children with dyslexia are slow to articulate a single speech gesture. Dyslexia. 2002;8(4):189-203.

20 Fletcher SG, Meldrum JR. Lingual function and relative length the lingual frenulum. J Speech Hear Res. 1968;11(2):382-90.

21 Fletcher SG. Time-by-count measurement of diadochokinetic syllable rate. J Speech Hear Res. 1972;15(4):763-70.

22 Hale ST, Kellum GD, Richardson JF, Messer SC, Gross AM, Sisakun S. Oral motor control, posturing, and myofunctional variables in 8-year-olds. J Speech Hear Res. 1992;35(6):1203-8.

23 Hartelius L, Lillvik M. Lip and tongue function differently affected in individuals with multiple sclerosis. Folia Phoniatr Logop. 2003;55(1):1-9.

24 Haselager GJT, Slis IH, Rietveld ACM. An alternative method of studying the development of speech rate. Clin Linguist Phon. 1991;5(1):53-63.

25 Henry CE. The development of oral diadochokinesia and non-linguistics rhythmic skills in normal and speech-disordered young children. Clin Linguist Phon. 1990;4(2):121-37.

26 Hirano M. Psycho-acoustic Evaluation of voice. In: Irano M. Clinical Examination of Voice. New York: Springer-Velag; 1981. p. 81-4. 
27 Irwin JV, Becklund O. Norms for maximum receptive rates for certain sounds established with the sylrater. J Speech Hear Disord. 1953;18(2):14960.

28 Kent RD, Kent JF, Rosenbek JC. Maximum performance tests of speech production. J Speech Hear Disord. 1987;52(4):367-87.

29 Kreul EJ. Neuromuscular control examination (NMC) for Parkinsonism: vowel prolongations and diadochokinetic and reading rates. J Speech Hear Res. 1972;15(1):72-83.

30 Leeper HA, Heeneman $\mathrm{H}$, Reynalds $\mathrm{C}$. Vocal function following vertical hemilaryngectomy: a preliminary investigation. J Otolaryngol. 1990;19(1):627.

31 Leeper HA, Jones E. Frequency and intensity effects upon temporal and aerodynamic aspects of vocal fold diadochokinesis. Percept Mot Skills. 1991;73(3 Pt 1):880-2.

32 Leeper HA, Millard KM, Bandur DL, Hudson AJ. An investigation of deterioration of vocal function in subgroups of individuals with ALS. J Med Speech Lang Pathol. 1996;4(3):163-81

33 Lewis BA, Freebairn LA, Hansen AJ, lyengar SK, Taylor HG. School-age follow-up of children with chilhood apraxia of speech. Lang Speech Hear Serv Sch. 2004;35(2):122-40.

34 Lundeen DJ. The relationship of Diadochokinesis to various speech sounds. J Speech Hear Disord. 1950;15:54-9 
35 Lundy DS, Roy S, Xue JW, Casiano RR, Jassir D. Spastic/spasmodic vs. tremulous vocal quality: motor speech profile analysis. J Voice. 2004;18(1):146-52.

36 Mason RM, Helmick JW, Unger JW, Gattozzi JG, Murphy MW. Speech screening of children in the dental office. J Am Dent Assoc. 1977;94(4):70812.

37 Meurer EM, Wnder MCO, Corleta HVE, Capp E. Voz e fala no menacme e na pós-menopausa. Rev Bras Saúde Matern Infant. 2004;4(3):281-6.

38 Mourão LF. Avaliação da fonoarticulação de pacientes com doença de Parkinson pré e pós- polidotomia [tese]. São Paulo (SP): Escola Paulista de Medicina, Universidade Federal de São Paulo; 2002.

39 Mulligan, et al. Intelligibility and acoustic charactieristics of speech in amyotrophic lateral sclerosis (ALS). J Speech Hear Res. 1994;37:496-503.

40 Murdoch EB. Desenvolvimento da fala e dos distúrbios da linguagem: uma abordagem neuroanatômica e fisiológica. Rio de Janeiro: Revinter; 1997

41 Nishio M, Niimi S. Changes over time in dysartric patients with amyotrophic lateral sclerosis (ALS): a study of changes in speaking rate and maximum repetition rate (MRR). Clin Linguist Phon. 2000;14(7):485-97.

42 Oliver RG, Jones MG, Smith SA, Newcombe RG. Oral sterognosis and diadochokinetic and young adults. Br J Disord Commun. 1985;20(3):271-80.

43 Parnell MM, Amerman JD. Perception of oral diadochokinetic performances in elderly adults. J Commun Disord. 1987;20(4):339-51. 
44 Pereira AC, Brasolotto AG, Berretin-Felix G, Padovani CR. Diadococinesia oral e laríngea em pacientes pós-acidente vascular encefálico. Pró-fono. 2004;16(3):283-292.

45 Portnoy RA, Aronson AE. Diadochokinetic syllable rate regularity in normal and in spastic and dysarthric subjects. J Speech Hear Disord. 1982;47(3):324-8.

46 Prathanee B, Thanaviratananich S, Pongjanyakul A. Oral diadochokinetic rates for normal Thai Children. Int J Lang Commun Disord. 2003;38(4):41728.

47 Prathanee B. Oral diadochokinetic rate in adults. J Med Assoc Thai. 1998;81(10):784-8.

48 Prins TD. Motor and auditory abilities in different groups of children with articulatory deviations. J Speech Hear Res. 1962;5(2):161-8.

49 Ptacek PH, Sander EK, Maloney WH, Jackson CCR. Phonatory and related changes with advanced age. J Speech Hear Res. 1966;9:353-60.

50 Ray J. Orofacial myofuncional therapy in dysarthria: a study on speech intelligibility. Int J Orofacial Myology. 2002;28:39-48.

51 Renout KA, Leeper HA, Bandur DL, Hudson AJ. Vocal fold diadochokinetic function of individuals with amyotrophic lateral sclerosis. Am J Speech Lang Pathol. 1995;4(1):73-80

52 Robb MP, Hughes MC, Frese DJ. Oral diadochokinesis in hearing-impaired adolescents. J Commun Disord. 1985;18(2):79-89. 
53 Robbins J, Klee T. Clinical assessment of oropharyngeal motor development in young children. J Speech Hear Disord. 1987;52:271-7.

54 Rosen KM, Kent RD, Duffy JR. Tasked-based profile of vocal intensity decline in Parkinson's disease. Folia Phoniatr Logop. 2005;57(1):28-37.

55 Shanks SJ. Effect of aging upon rapid syllable repetition. Percept Mot Skills. 1970;30(3):687-90.

56 Thonnen G, Maassen B, Wit J, Gabreels F, Schreuder R. The integrated use of maximum performance tasks in differential diagnostic evaluation among children with motor speech disorders. Clin Linguist Phon. 1996;10(4):311-36.

57 Thonnen G, Maassen B, Wit J, Gabreels F, Schreuder R. Validity of maximum performance tasks to diagnose motor speech disorders in children. Clin Linguist Phon. 1999;13(1):1-23.

58 Towne RL. Effect of mandibular stabilization on the diadochokinetic performance of children with phonological disorder. J Phon. 1994;22:317332.

59 Wertzner HF. Fonologia. In: Andrade CRF de, Béfi-Lopes DM, Fernandes FDM, Wertzner HF. ABFW: teste de linguagem infantil nas áreas de fonologia, vocabulário, fluência e pragmática. 2. ed. Carapicuíba: Pró-Fono; 2004. p. 5-32.

60 Whitehill TA, Tsahng E S-L. Relationship between diadochokinetic and speech measures in hypokinetic speakers. J Med Speech Lang Pathol. 2002;10(4):333-8. 
61 Williams P, Stackhouse J. Diadochokinetic skills: normal and typical performance in children aged 3-5 Years. Int J Lang Commun Disord. 1998;33Suppl: 481-6.

62 Williams P, Stackhouse J. Rate, accuracy and consistency: diadochokinetic performance of young, normally developing children. Clin Linguist Phon. 2000;14(4):267-93.

63 Williams R, Ingham RJ, Rosenthal J. A further analysis for developmental apraxia of speech in children with defective articulation. J Speech Hear Res. $1981 ; 24(4): 496-505$.

64 Wit J, Maassen B, Gabreels F, Thoonen G, de Swart B. Traumatic versus perinatally acquired dysathria: assessment by means of speech-like maximum performance tasks. Dev Med Child Neurol. 1994;36(3):221-9.

65 Wit J, Maassen B, Gabreels FJ, Thoonen G. Maximun performance tests in children with developmental spastic dysartria. J Speech Hear Res. 1993;36(3):452-9.

66 Wolk L, Edwards ML, Conture EG. Coexistence of stuttering and disordered phonology in young children. J Speech Hear Res. 1993;36(5):906-17.

67 Yaruss JS, Logan KJ. Evaluating rate, accuracy, and fluency of young children's diadochokinetic productions: a preliminary investigation. J Fluency Disord. 2002;27(1): 65-86.

68 Yoss KA, Darley FL. Developmental apraxia of speech in children with defective articulation. J Speech Hear Res. 1974;17(3):399-416. 
69 Ziegler W. Task-related factors in oral motor control: speech and oral diadochokinesis in dysarthria and apraxia of speech. Brain Lang. 2002;80(3): 556-75. 
ABSTRACT 


\section{ABSTRACT}

\section{ORAL AND LARYNGEAL DIADOCHOKINESIS IN CHILDREN}

Diadochokinesis (DDK) is the ability to perform fast repetitions of relatively simple patterns of opposite muscle contractions and it is employed for the evaluation of the neuromotor maturation and integration. The oral and laryngeal DDK, associated with other procedures for the speech evaluation, are important resources in the understanding of communication disorders. Thus, this study was conducted to establish reference values of normality of the outcomes of oral and laryngeal DDK for the different genders and age ranges of Brazilian Portuguese-speaking children, as well as to analyze the presence of difference between genders and among age ranges. The study sample was composed of 150 children aged 8, 9 and 10 years. The oral DDK was evaluated by repetition of "pa", "ta", "ka" and "pataka", and laryngeal DDK was assessed by repetition of "a" and "i". The softwares Motor Speech Profile Advanced and Mult Speech Main Program, of Kay Elemetrics Corp, were employed analysis. The DDK parameters were presented as mean, median and percentile for each emission. Comparison among genders and age ranges was performed by twoway analysis of variance and the Tukey test. Statistical analysis of oral DDK revealed with an increase in age: there were an increase in the number of emissions of monosyllables per second, a reduced mean time between emissions; an increase in the coefficient of variation of the period during the syllable "ka", and an increase in the coefficient of variation of the peak intensity for the syllable "ta". The number of emissions of the syllable "ta" per second was higher for females than to males. In the trisyllabic emission, the number of emissions per second was different among the genders. Besides, regarding the subgroups of age and gender, the 8 year-old-girls showed a decreased number of emissions than the other subgroups. With regard to laryngeal DDK, there was an increased number of emissions per second and shorter periods of vowel "i" for females with the increase in age; there was also a smaller standard deviation and perturbations of the period on for this same vowel. It was concluded that it was possible to establish values of normality of oral and laryngeal DDK for the group of children investigated; and that there were differences as to gender and age, which demonstrates that the development of oral and laryngeal DDK should be considered in the evaluation of oral communication of children.

Key words: Evaluation. Speech articulation tests. Voice. 
APÊNDICE 
APÊNDICE 1 - Ofício de aprovação do projeto de pesquisa pelo Comitê de Ética em Pesquisa, da Faculdade de Odontologia de Bauru, da Universidade de São Paulo (Proc. №. 127/2005).

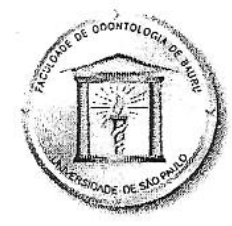

\section{Universidade de São Paulo Faculdade de Odontologia de Bauru}

Al. Dr. Octávio Pinheiro Brisolla, 9-75 - Bauru-SP - CEP 17012-901 - C.P. 73 PABX (0XX14)3235-8000 - FAX (0XX14)3223-4679

Comitê de Éfica em Pesquisa

Processo $n^{\circ} 127 / 2005$

Bauru, 02 de dezembro de 2005.

Senhora Professora,

O projeto de pesquisa encaminhado a este Comitê de Ética em Pesquisa em Seres Humanos, denominado "Diadococinesia oral e laríngea em crianças", de autoria de Daniela Jovel Modolo, que será desenvolvido sob sua orientação, foi enviado ao relator para avaliação.

$\mathrm{Na}$ reunião de 30 de novembro de 2005 o parecer do relator, aprovando o projeto, foi aceito pelo Comitê, considerando que não existem infrações éticas pendentes.

Informamos que após o envio do trabalho concluido, este Comitê enviará o parecer final, que será utilizado para publicação do trabalho.

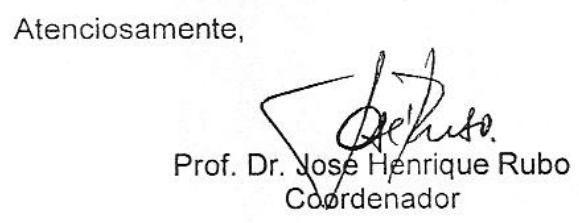

IIm ${ }^{\text {a }} \mathrm{Sr}^{\mathrm{a}}$ Prof $^{\mathrm{a}} \mathrm{Dr}^{\mathrm{a}}$ Alcione Ghedini Brasolotto

DD. Docente do Departamento de Fonoaudiologia 